\title{
CRESCIMENTO VERSUS DESENVOLVIMENTO LOCAL: UMA ANÁLISE ENTRE O PIB E A RENDA MÉDIA DOS MUNICÍPIOS DO RIO GRANDE DO NORTE
}

\author{
H. E. de OLIVEIRA e M. F. F. S. TACCONI. \\ Instituto Federal de Educação, Ciência e Tecnologia do Rio Grande do Norte \\ herculespotiguar@hotmail.com e marli.tacconi@ifrn.edu.br \\ Artigo submetido em 26/07/2018 e aceito em 01/08/2018 \\ DOI: $10.15628 /$ empirica.2018.7538
}

\section{RESUMO}

O crescimento e o desenvolvimento local influenciam diretamente na qualidade de vida da população, como também, possibilita oportunidades para novos investimentos. Este artigo pretende observar esta possível relação através de uma pesquisa exploratória e descritiva sobre esta reflexão. Utilizando-se alguns índices e dados coletados, esta pesquisa procura esclarecer possíveis desencontros entre o Produto Interno Bruto e variáveis dependentes como a Renda Média, a Estimativa de População e o IDH médio dos 167 municípios que formam o Estado do Rio Grande do Norte. Como objeto de estudo, serão expostos, os principais dados coletados dos 10 municípios mais desenvolvidos e os 10 menos desenvolvidos segundo cada variável analisada neste contexto. Finalmente, procura-se através desta pesquisa analisar os principais desencontros observados neste estudo, pretendendo-se com tal ação, propor aos gestores, pesquisadores e demais interessados nesta temática, possibilidades de mudanças estratégicas visando um crescimento e desenvolvimento local mais equilibrado, de acordo com o potencial de seu município. Conclui-se que o Rio Grande do Norte possui um grande potencial local, concentrado em pequenos nichos ligados a setores específicos como: indústria, turismo, extração (mineral, sal e petróleo) e importação. Em alguns municípios a disparidade entre o PIB e a Renda Média é observada diante da falta de infraestrutura adequada, não permitindo o desenvolvimento equilibrado e com isso, o giro de capital não é observado nas cidades menores, muito menos a Renda Média reflete o real potencial do município.

PALAVRAS-CHAVES: Desenvolvimento Local, PIB, Renda Média, Estimativa de Produção.

\section{GROWTH VERSUS LOCAL DEVELOPMENT: AN ANALYSIS BETWEEN GDP AND THE AVERAGE INCOME OF THE MUNICIPALITIES OF RIO GRANDE DO NORTE}

\section{ABSTRACT}

Local growth and development directly influence the quality of life of the population, as well as providing opportunities for new investments. This article intends to observe this possible relation through an exploratory and descriptive research on this reflection. Using some indexes and data 
collected, this research seeks to clarify possible disagreements between the Gross Domestic Product and dependent variables such as Average Income, Population Estimate and the average HDI of the 167 municipalities that make up the State of Rio Grande do Norte. As the object of study, the main data collected from the 10 most developed municipalities and the 10 least developed ones will be exposed according to each variable analyzed in this context. Finally, this research seeks to analyze the main disagreements observed in this study, aiming at such action, to propose to managers, researchers and other stakeholders in this theme, possibilities for strategic changes aimed at a more balanced growth and local development, according to the potential of your municipality. It is concluded that Rio Grande do Norte has great local potential, concentrated in small niches linked to specific sectors such as: industry, tourism, extraction (mineral, salt and oil) and import. In some municipalities, the disparity between GDP and Average Income is observed in the absence of adequate infrastructure, which does not allow a balanced development and with this, capital turnover is not observed in smaller cities, much less the Average Income reflects the real potential of the municipality.

KEY WORDS: Local Development, GDP, Average Income, Production Estimation.

\section{INTRODUÇÃO}

De acordo com os principais noticiários e fontes de pesquisas apresentadas por órgãos competentes como IBGE, FJV, DIEESE entre outros, observa-se nos últimos 5 anos uma forte iniciativa do Governo Federal em elevar o status do nosso país e equipará-lo com os países mais desenvolvidos, considerados como "primeiro mundo", investindo em políticas públicas voltadas para o assistencialismo, educação, turismo, infraestrutura, entre outras medidas, de forma que os números possam mostrar uma nova realidade, como vem sendo perseguida nos últimos Governos (SANTOMAURO; BIBIANO, 2009).

No entanto, é necessário analisar se essas políticas públicas são efetivas nos estados e munícipios brasileiros, porque nem sempre as ações que são planejadas e executadas geram crescimento e desenvolvimento local. Existem diversos fatores culturais, sociais, econômicos dentre outros que impactam na execução das ações públicas.

Considerando o Rio Grande do Norte, este é um Estado bastante heterogêneo diante de suas características sociais, culturais e econômicas. Várias são as atividades exploradas em seu território, desde as atividades ligadas diretamente à pesca e à extração do petróleo e sal, no litoral, à agropecuária, agricultura, turismo, fruticultura, extração de minérios, entre outras atividades (AZEVEDO, 2013).

Essa diversidade, no entanto, apresenta dados completamente distintos ao potencial de muitos municípios, no qual a renda média é observada de forma desproporcional em relação ao seu Produto Interno Bruto, por exemplo, que não condiz com o real desenvolvimento do município.

Atualmente, o Rio Grande do Norte passou a desenvolver critérios de avaliação quanto ao seu crescimento e desenvolvimento bastante duvidosos, como exigências do próprio Governo Federal, buscando-se atingir metas internacionais que justificassem o seu desenvolvimento em comparação com dados estatísticos de países desenvolvidos. Trata-se de um Estado no qual o Índice de Desenvolvimento Humano (IDH), segundo dados do IBGE (2016), é considerado médio para todos os 
167 municípios da unidade da Federação. O IDH avalia o bem-estar humano a partir de uma perspectiva que vai além do rendimento das pessoas, uma vez que desenvolvimento significa muito mais que isso, como por exemplo, a maximização das escolhas, o pleno acesso aos direitos humanos, possibilidade de uma vida longa, saudável e criativa. O IDH incide sobre três dimensões básicas do desenvolvimento humano: uma vida longa e saudável, medida pela esperança de vida durante o nascimento; capacidade de adquiri conhecimento, medida pela média de anos de escolaridade e anos de escolaridades esperados; como também, pela capacidade de atingir um nível de vida digno, medido pelo rendimento nacional bruto per capita (PNUD, 2015).

Diante disso, este artigo possui o objetivo de analisar a relação crescimento versus desenvolvimento dos municípios do Estado do Rio grande do Norte, segundo dados específicos, tais como: PIB, Renda Média, estimativa de População e IDH Médio. Para tanto, necessita-se buscar informações que permitam uma análise mais eficiente, através de dados coletados em fontes, como: IBGE, FGV, BNDE, entre outros, para a elaboração das informações necessárias para este estudo. Neste contexto, o universo pesquisado é formado por 167 municípios. Destes, foram analisados os dados dos 10 maiores municípios em desenvolvimento e, ao mesmo tempo, os 10 menores municípios de acordo com cada índice analisado.

A relevância desse trabalho para a Academia pode ser observada diante da necessidade de discussão e análise sobre a qualidade da gestão pública que os municípios do Estado do Rio Grande do Norte possuem, diante a sua capacidade efetiva de crescimento e desenvolvimento, uma vez que a maioria destes gestores não possui conhecimentos dos próprios dados e informações necessárias de seus próprios municípios. Por outro lado, existe o paradigma de acreditar que o crescimento e desenvolvimento de determinado município encontra-se diretamente relacionado ao seu PIB, quando na verdade, este estudo procura desmistificar esta hipótese considerada como ideal, mas que precisa ser analisada através dos dados a que se propõe estudar através deste artigo.

Para a sociedade, trata-se de mais um acervo de pesquisa que poderá servir como debate e um olhar mais apurado sobre a gestão da coisa pública. Diante dos desafios surgidos com as novas tecnologias e o advento da globalização, a gestão pública não pode ser observada de forma amadora e irresponsável. Precisa-se no mínimo, que os gestores invistam em pesquisas e desenvolvimento, possua uma equipe de assessores capacitados que possam garantir a eficiência, a eficácia e a efetividade da gestão pública municipal. Os dados e as informações trabalhadas neste artigo poderão servir como reflexão para futuras estratégicas de planejamento e desenvolvimento de estratégias locais, com o apoio da própria sociedade civil.

\section{CRESCIMENTO E DESENVOLVIMENTO: PRINCIPAIS CONCEITOS}

Quando se trata de crescimento e desenvolvimento de um determinado município brasileiro, não se pode esquecer que este assunto encontra-se diretamente ligado à gestão do setor público propriamente dito. E antes de versar sobre estes conceitos, torna-se relevante observar o que Orates (1972 apud LIMA, 2011, p. 28) esclarece em sua análise: 


\section{ISSN - 2447-178X}

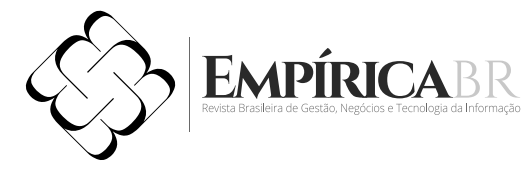

O setor público tem três problemas econômicos primários para resolver se o sistema deve conduzir a um bem-estar ótimo: a realização de uma melhor distribuição equitativa de renda (o problema da distribuição) e o estabelecimento de um padrão eficiente de uso de recurso (o problema da alocação). Esse último problema, a propósito, inclui assegurar que a economia alcance uma alocação eficiente de recursos por meio do tempo ou, em outras palavras, taxa e padrão eficientes de crescimento.

Tendo em vista que esse argumento encontra-se diretamente relacionado sobre as funções de estabilização e distribuição que devem ser centralizados pelo Governo Federal, objetivando maior capacidade de produção satisfatória de fatores determinantes tais como: emprego, estabilidade nos preços, melhor distribuição igualitária de renda, entre outros.

O crescimento econômico indica aumento da produção e da capacidade de atendimento, com aumento da estrutura, da mão de obra e dos processos, enquanto o desenvolvimento econômico é observado por Fonseca (2006, p. 4) como um processo "relativamente recente, pois coincide com o aparecimento do capitalismo e, mais propriamente, com o advento da Revolução Industrial". Segundo este autor, os sistemas pré-capitalistas eram marcados pela estagnação econômica, já que não existia a cultura de acumulação nem de crescimento de produção, portanto, antes da Revolução Industrial não se falava em desenvolvimento econômico.

Complementando essa ideia, Veiga (2010, p. 801), sobre o conceito de desenvolvimento econômico, afirma que:

O desenvolvimento econômico tem a ver, primeiro e acima de tudo, com a possibilidade de as pessoas viverem o tipo de vida que escolheram, e com a provisão dos instrumentos e das oportunidades para fazerem as suas escolhas.

Este enunciado possibilita uma amplitude maior da importância em se observar o crescimento econômico, não apenas de um determinado país ou nação, como também, parte dele, como é o caso dos municípios do estado do Rio Grande do Norte, utilizados como objeto de pesquisa neste trabalho científico, uma vez que o crescimento pode mascarar todas as ineficiências, principalmente quando observa-se o crescimento de uma cidade, no mesmo instante em que a sua competitividade não consegue acompanhar tal crescimento, diante da falta de recursos financeiros, falta de investimentos, geração de renda, entre outros motivos.

De acordo com o entendimento de Bresser-Pereira (2006, p. 9), o desenvolvimento econômico pode ser finalmente definido como

o processo histórico de crescimento sustentado da renda ou do valor adicionado por habitante implicando a melhoria do padrão de vida da população de um determinado estado nacional, que resultada sistemática acumulação de capital e da incorporação de conhecimento ou progresso técnico à produção. Nestes termos, o desenvolvimento 


\section{ISSN - 2447-178X}

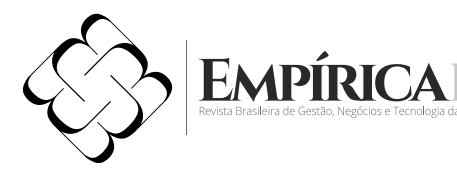

econômico é um processo de transformação que implica mudanças nos três níveis ou instâncias de uma sociedade: estrutural, institucional ou cultural. É o aumento sustentado dos padrões de vida possibilitado pelo aumento da produtividade de determinadas atividades e/ou pela transferência da mão-de-obra dessas para outras atividades com maior valor adicionado per capita porque envolvendo maior conhecimento. É o aumento dos salários causado direta ou indiretamente por esse aumento da produtividade e essa concentração da população de um estado-nação nas atividades de maior valor adicionado.

A partir deste contexto, torna-se viável observar a questão do desenvolvimento econômico local, diante dos conceitos apresentados e observando a realidade dos municípios do Rio Grande do Norte em relação ao seu respectivo Produto Interno Bruto (PIB).

Sobre o conceito de crescimento local, Buarque (2001 p. 25) conceitua como:

Um processo endógeno registrado em pequenas unidades territoriais e agrupamentos humanos capaz de promover o dinamismo econômico e a melhoria da qualidade de vida da população. Representa uma singular transformação nas bases econômicas e na organização social em nível local, resultante da mobilização das energias da sociedade, explorando as suas capacidades e potencialidades específicas.

Complementando esta discussão, Amaral et al. (2010, p. 208), esclarecem que "uma das condições para o desenvolvimento local está no processo endógeno de crescimento e consumo".

\section{VARIÁVEIS E ÍNDICES DE ANÁLISE DE CRESCIMENTO E DESENVOLVIMENTO}

Existem diversas formas de mensuração do crescimento e desenvolvimento de um determinado município ou região. No entanto, para esta pesquisa torna-se relevante apresentar os conceitos de Covariância, Produto Interno Bruto, Estimativa da população, Índice de Desenvolvimento Humano e Renda Média.

A covariância verifica a relação entre duas variáveis. Se a covariância for nula, significa que as variáveis analisadas são independentes. Se for diferente de zero, as variantes podem apresentar determinada dependência entre si. A covariância costuma ser chamada de medida de dependência linear entre duas variáveis aleatórias. Apesar de esse conceito ser bastante introdutório, uma vez que os conceitos envolvidos nos cálculos de covariância dependem de outros conceitos, ele serve para amparar a sua função nesta pesquisa. Em relação ao significado dos resultados de covariância, tornase relevante as seguintes observações:

1. Quando a covariância é positiva, as duas variáveis analisadas tendem a variar na mesma direção e, portanto, se uma aumenta, a outra tende a aumentar também, assim como, se uma cai, a outra 
também tende a diminuir. Dessa forma, a covariância positiva indica que as duas variáveis caminham juntas mediante as variações que ocorrerem em cada uma.

2. Quando houver covariância negativa, significa que há duas variáveis que tendem a variar em direções opostas. Neste caso, se há aumento em uma das variantes, a outra deverá apresentar diminuição, ou se uma diminuir, a outra tenderá a aumentar o seu valor. Dessa forma, a covariância negativa afirma categoricamente que existe uma oposição entre os movimentos das duas variáveis analisadas.

3. Quanto mais próxima de zero for o resultado da covariância obtida, menor será a possibilidade de encontrar um comportamento de interdependência linear entre as variáveis, assim como, quanto mais próximo de 1 for o seu valor, maior será a sua interdependência.

Com relação ao Produto Interno Bruto (PIB), este corresponde ao valor do output total de todos os bens produzidos internamente numa economia ao longo de um determinado período de tempo, geralmente considerado para fins de comparação, de um ano. 0 termo "bruto" neste contexto significa que o valor da depreciação ou do desgaste do capital utilizado na produção não foi deduzido do valor do output final (NUNES, 2016a).

Trata-se, em outras palavras, da soma de todos os serviços e bens produzidos num determinado período, geralmente um ano, numa determinada região (continente, país, estado ou cidade), expresso em valores monetários, que serve como importante indicador da atividade econômica desta referida região em questão, representando o seu crescimento econômico.

A Estimativa de População segundo o IBGE (1991) se trata de um dos dados mais importantes dentro da estatística, para acompanhar pari passu as projeções populacionais de uma determinada região (continente, país, estado ou cidade). As projeções populacionais mensais, com data de referência nos dias primeiro de cada mês, são obtidas, inicialmente, mediante um ajuste geométrico aos valores projetados pelo método das componentes demográficas que cobrem determinado período.

Sobre a questão de se calcular tais projeções, Howe (2004) chama a atençao para o fato de que a definição de erro aceitável não se trata de uma tarefa clara e, em alguns casos, pode parecer subjetiva. No entanto, diversas características como tamanho da população, taxa de crescimento, horizonte de projeção, entre outras, irão influenciar na definição de um percentual mínimo de erro. Segundo este autor, para uma pequena população de 2.000 habitantes, por exemplo, um erro de $5 \%$ poderá ser aceitável. No entanto, diante de uma população mais representativa, como por exempo, 200.000 habitantes, essa margem poderá não ser aceitável. Além do mais, torna-se evidente que, a medida que o horizonte aumenta, o erro também cresce.

De posse da função determinada torna-se possível interpolar mensalmente as populações projetadas entre os respectivos anos. No Brasil, os métodos de projeção populacional para pequenos domínios (municípios) considerados de boa precisão têm sido aqueles em que mais da metade dos municípios apresentam EP entre -10\% e 10\%.

O Índice de Desenvolvimento Humano pode ser conceituado, segundo Nunes (2016b) como um indicador de desenvolvimento criado por Amarthya Sen, economista indiano galardoado com o Prémio Nobel da Economia em 1998. O IDH inclui, além dos dados económicos, outros dados relacionados com a educação ou a saúde, nomeadamente: 


\section{ISSN - 2447-178X}

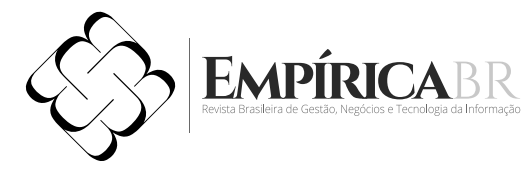

- PIB p.c. real (medido em paridade de poder de compra)

- Esperança média de vida à nascença

- Taxa de alfabetização de adultos e taxa de escolaridade combinada dos ensinos primário, secundário e superior.

Este índice é calculado com base em dados econômicos e sociais, variando o seu valor de 0 (nenhum desenvolvimento humano) a 1 (desenvolvimento humano total. Dessa forma, quanto mais perto de 1 for a região em questão, mais desenvolvida será.

De acordo com dados do Programa das Nações Unidas para o Desenvolvimento (PNUD), para 2011 o IDH do Brasil é 0,718. Embora apresente deficiências no sistema educacional, o IDH do Brasil é considerado de alto desenvolvimento humano, pois o país vem apresentando bons resultados econômicos e sociais. No entanto, este índice tem sofrido algumas críticas por parte da ONU, por não considerar os extremos superiores e inferiores, uma vez que este índice não abrange todos os aspectos de desenvolvimento e não se trata de uma representação da 'felicidade das pessoas', muito menos indica o melhor lugar do mundo para se viver. No caso dos municípios do RN, independentemente da sua condição geral de desenvolvimento, possuem sem exceção um IDH médio entre 0,530 e 0,766 (PNUD, 2012).

A deficiência educacional observada no Brasil trata-se de uma das características próprias de países em desenvolvimento, que caminha lado a lado com a enorme desigualdade da distribuição de renda. Na realidade, estes dois problemas possuem uma relação muito forte entre si. Não tem como educar adequadamente uma criança cuja família vive em situação de miséria, como também, não tem como garantir uma educação de qualidade apenas construindo escolas, sem resolver a questão da pobreza no Brasil (GOLDEMBERG, 1993).

A renda média aqui utilizada trata-se da divisão do Produto Interno Bruto de cada município dividido pela população. Segundo o IBGE (2016), para a avaliação da dimensão renda, o critério usado é a renda municipal per capita, ou seja, a renda média de cada residente no município. Para se chegar a esse valor soma-se a renda de todos os residentes e divide-se o resultado pelo número de pessoas que moram no município (inclusive crianças ou pessoas com renda igual a zero). No caso do Brasil, o cálculo da renda municipal per capita é feito a partir das respostas ao questionário expandido do Censo - um questionário mais detalhado do que o universal e que é aplicado a uma amostra dos domicílios visitados pelos recenseadores. Os dados colhidos pelo IBGE através dessa amostra do Censo são expandidos para o total da população municipal e, então, usados para o cálculo da dimensão renda do IDH-M.

Diante dos conceitos aqui estudados, necessita-se a partir deste momento analisar os dados coletados para a avaliação do crescimento e desenvolvimento dos principais municípios do Rio Grande do Norte.

Para se entender a origem do conceito sobre crescimento econômico, necessita-se um estudo epistemológico acerca da sua evolução histórica e contextualização. Hunt (2005) esclarece que o termo crescimento econômico se originou como fonte de estudo e pesquisa, a partir de $1776 \mathrm{com}$ a publicação da obra de Adan Smith, intitulada A Riqueza das Nações, quando pela primeira vez, torna-se 
acessível o estudo de tal fenômeno à luz do funcionamento dos mercados e a relação de expansão destes, para ganhos de escala de produção, onde permitia-se gerar lucros através da redução dos custos médios. Defendendo este aspecto, Hunt (2005, p. 54) afirma que:

No contexto da teoria da história, de Smith, o capitalismo representava o estágio mais alto da civilização e atingiria seu ponto culminante quando tivesse evoluído para um estado em que o governo tivesse adotado uma política de laissez-faire, permitindo que as forças da concorrência e o livre jogo da oferta e da demanda regulassem a economia, que ficaria quase que completamente livre das restrições do governo ou de suas intervenções.

Segundo a tese deste autor, a acumulação do capital, livre das restrições supracitadas, tornar-se-ia a principal fonte de progresso econômico, de forma que os lucros passariam a ser observado como fonte principal do novo capital.

Não é o objetivo deste artigo o aprofundamento estatístico sobre os dados aqui representados ou os conceitos sobre os índices envolvidos, uma vez que, durante o desenvolvimento deste estudo foram utilizados dados previamente coletados e calculados, que servirão como elementos norteadores das reflexões apresentadas neste contexto. No entanto, através da descrição e análises destes dados, será possível alcançar o objetivo proposto de analisar a relação crescimento e desenvolvimento dos 10 municípios do Rio Grande do Norte mais desenvolvimentos, como também, dos 10 menos desenvolvidos.

Os resultados podem ser observados apenas diante de uma análise pouco minuciosa por parte de qualquer indivíduo em contato com estes resultados, como acontece com parte da população diante de um noticiário televisivo, por exemplo. No entanto, para que esta pesquisa tenha cunho científico, necessita-se de uma reflexão mais detalhada ou mais discutida sobre esta questão, principalmente entre acadêmicos e pesquisadores, incentivando-os a uma busca constante por novos desafios e resultados, principalmente quando se percebe que a maioria dos gestores públicos municipais brasileiros não possui qualificação profissional ou conhecimentos desejados para atuarem a favor dos municípios para os quais foram eleitos.

\section{METODOLOGIA}

Dentro dessa perspectiva, foram analisadas as principais características dos melhores e piores municípios do Rio Grande do Norte, em relação a cada índice analisado: Produto Interno Bruto (PIB), Índice de Desenvolvimento Humano (IDH), Renda Média e Estimativa de População. A discussão dessa análise se desenvolverá principalmente diante da análise dos 10 melhores e piores municípios para cada índice analisado, para que se possa tecer algumas comparações com os resultados apresentados entre os índices no que se refere a posição dos municípios em cada um deles. 


\title{
ISSN - 2447-178X
}

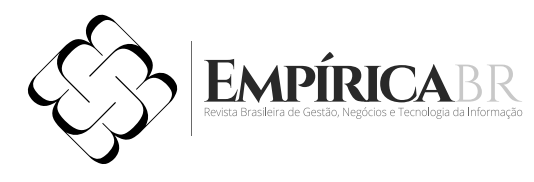

Esta pesquisa possui um caráter exploratório e descritivo, uma vez que, segundo Selltizetal (1967, p. 63 apud GIL, 2010, p. 27) as pesquisas exploratórias possuem o seguinte objetivo:

\author{
Proporcionar maior familiaridade com o problema, com vistas a torna-lo mais explícito \\ ou a construir hipóteses. Seu planejamento tende a ser bastante flexível, pois interessa \\ considerar os mais variados aspectos relativos ao fato ou fenômeno estudado.
}

Sobre a questão desta pesquisa também ser considerada com descritiva, Gil $(2010$, p. 27) tece o seguinte comentário:

\begin{abstract}
As pesquisas descritivas têm como objetivo a descrição das características de determinada população. Podem ser elaboradas também, com a finalidade de identificar possíveis relações entre variáveis. São em grande número as pesquisas que podem ser classificadas como descritivas e a maioria das que são realizadas com objetivos profissionais provavelmente se enquadra nesta categoria.
\end{abstract}

Como exemplo deste tipo de pesquisa, o autor cita aquelas que possuem como objetivo, estudar as características de um grupo, como por exemplo, sua distribuição por idade, sexo, procedência, nível de escolaridade, entre outros. No caso em questão, este trabalho estuda aspectos relacionados ao e desenvolvimento econômico.

Quanto à técnica, foi realizado um levantamento, por abranger o problema central do crescimento versus desenvolvimento dos municípios do Estado do Rio Grande do Norte, analisando as cidades mais desenvolvidas, comparando-se com as menos desenvolvidas neste contexto.

Neste trabalho de pesquisa foram utilizadas fontes secundárias na coleta de informações a respeito dos dados estatísticos necessários para a elaboração deste artigo, tais como: sites do IBGE, PNUD, Sistema FIERN, entre outros, como também, através de dados ou informações relevantes em livros e artigos em revistas especializadas sobre o tema. Quanto ao método empregado, trata-se de uma pesquisa documental.

Neste contexto, o universo é formado pelos 167 municípios do estado do Rio Grande do Norte. A amostra é formada pelos 10 melhores municípios destacados através dos seguintes índices de análise de crescimento e desenvolvimento: Produto Interno Bruto (PIB), Índice de Desenvolvimento Humano (IDH), Renda Média e Estimativa de População. Ao mesmo tempo, serão analisados os 10 piores municípios diante destes mesmos objetos de classificação.

Os dados coletados foram tabulados e tratados através da utilização de planilhas eletrônicas do software Microsoft Excel, versão 2015, sendo posteriormente analisados diante dos gráficos gerados para a análise das informações coletadas, de forma quantitativa, por permitir classificar e analisar os dados e informações coletadas e qualitativa, procurando evidenciar os resultados e obter conhecimentos sobre o desenvolvimento dos municípios no Estado do Rio Grande do Norte. (MEDEIROS, 2008). 


\section{ISSN - 2447-178X}

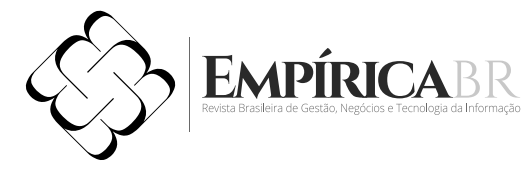

O Produto Interno Bruto (PIB) dos municípios do Rio Grande do Norte, utilizado para análise foi apresentado pelo IBGE/IDEMA para o ano de 2014. Nesta pesquisa, trata-se do principal índice de análise para que os municípios classificados nos demais índices possam serem confrontados e verificado seu comportamento diante da situação de crescimento e desenvolvimento de cada município analisado (IBGE/IDEMA, 2014).

O Índice de Desenvolvimento Humano foi extraído do IBGE Cidades, diretamente da página que apresenta os resultados de cada município, tendo como base o ano de 2016. Nesta mesma plataforma de informações foram coletadas a Estimativa de População, já calculada e mensurada na página de cada município (IBGE, 2016).

Finalmente, a Renda Média domiciliar per capita de cada município foi coletada diante dos dados apresentados pelo IBGE/DATASUS, correspondente ao ano de 2010, para cada município do Rio Grande do Norte (IBGE, 2010).

\section{ANÁLISE E INTERPRETAÇÃO DOS DADOS}

De acordo com os dados e informações coletadas dos 167 municípios do Estado do Rio Grande do Norte, para esta pesquisa foram considerados apenas os dados dos 10 municípios mais desenvolvidos e os 10 menos desenvolvidos, de acordo com os dados apresentados pelas variáveis de crescimento e desenvolvimento analisadas. Para uma análise mais minuciosa, os dados de cada variável apresentada serão confrontados com os dados do PIB, tanto para os municípios mais desenvolvidos quanto para os menos desenvolvidos,

\subsection{Produto Interno Bruto dos municípios mais desenvolvidos do RN}

Considerando-se anteriormente o Produto Interno Bruto de todos os 167 municípios do RN e com o auxílio de planilhas eletrônicas do software Microsoft Excel, versão 2015, foram encontrados uma média de $\mathrm{R} \$ 323.554,40$ e uma mediana de $\mathrm{R} \$ \mathbf{6 2 . 9 8 3 , 2 6}$ diante de um desvio padrão de $\mathrm{R} \$ \mathbf{1 . 5 8 4 . 9 3 3 , 2 5}$. Estes dados indicam um caso de assimetria positiva, uma vez que a mediana é inferior à média.

Entre os municípios mais desenvolvidos, percebe-se que a maioria representa o polo industrial do Estado do Rio Grande do Norte, como também, podem ser considerados como principais polos turísticos, principalmente os que se localizam no litoral. Diante disso, torna-se fácil a compreensão dos dados apresentados sobre o Produto Interno Bruto, na Tabela 1. 


\section{ISSN - 2447-178X}

Tabela 1: Produto Interno Bruto dos municípios mais desenvolvidos do RN

\begin{tabular}{l|l}
\multicolumn{1}{c|}{ Município } & \multicolumn{1}{c}{\begin{tabular}{c}
\multicolumn{1}{c}{ PIB } \\
(em milhões)
\end{tabular}} \\
\hline Natal & $19.076 .030,47$ \\
\hline Mossoró & $6.221 .099,05$ \\
\hline Parnamirim & $4.408 .474,16$ \\
\hline São Gonçalo do Amarante & $1.630 .595,15$ \\
\hline Macaíba & $1.358 .253,53$ \\
\hline Caicó & $930.891,52$ \\
\hline Macau & $914.350,27$ \\
\hline Açu & $890.710,40$ \\
\hline Areia Branca & $819.391,33$ \\
\hline Ceará-Mirim & $710.929,04$ \\
\hline
\end{tabular}

Fonte: IBGE/IDEMA (2014).

Analisando estes mesmos dados através da Figura 1, fica mais fácil observar a disparidade existente entre os principais municípios do Estado, considerados como mais desenvolvidos segundo o seu PIB, com um grande destaque para Natal, Mossoró e Parnamirim, respectivamente.

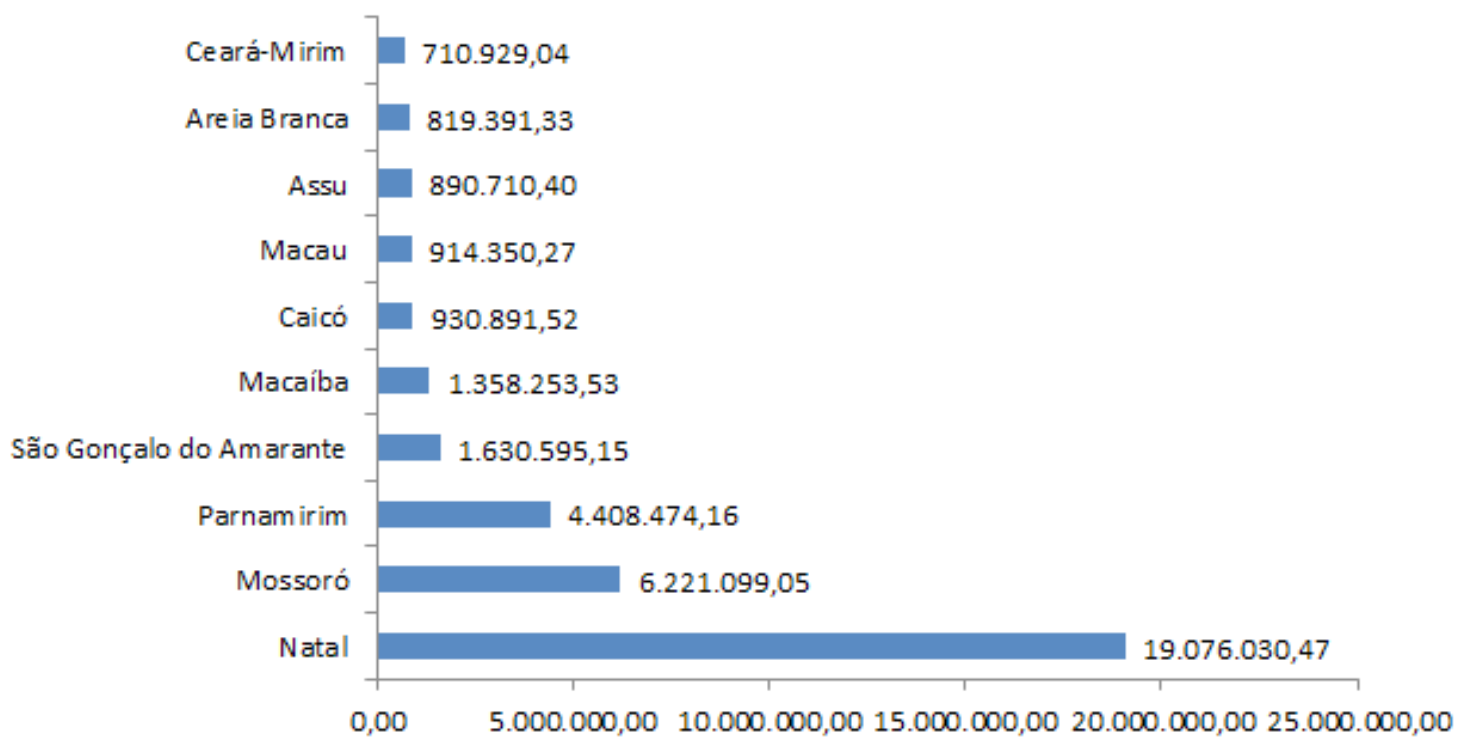

Figura 1: Produto Interno Bruto (em milhões) dos municípios do RN mais desenvolvidos

Como política de desenvolvimento local, observa-se a falta de infraestrutura nas cidades analisadas, para que as pessoas oriundas de outras cidades possam residir e participar do desenvolvimento econômico da cidade. A falta de escolas, hospitais, mobilidade urbana, rede bancária entre outras providências influenciam diretamente na renda média dessas cidades que possuem o PIB alto, no entanto, que não consegue se desenvolver no mesmo ritmo como Natal, Mossoró e Parnamirim, por exemplo. (CANEN, 2012). 


\subsection{Renda Média dos municípios mais desenvolvidos do RN}

Seguindo a mesma forma de análise realizada para o PIB, antes de tratar dos municípios mais desenvolvidos segundo a sua Renda Média e considerando esta variável para os dados coletados de todos os 167 municípios foram observados uma média de $\mathrm{R} \$ 323.554,40$ e uma mediana de $\mathrm{R} \$$ $62.983,28$. Estes dados revelam a realidade do Estado em termos de distribuição de renda, identificando que grande parcela dos municípios não possui boas perspectivas de desenvolvimento. Ao observar a correlação existente entre o Produto Interno Bruto destes mesmos municípios e a sua Renda Média, descobre-se uma correlação de 0,7778.

Tabela 2: Produto Interno Bruto versus Renda Média dos municípios mais desenvolvidos do RN

\begin{tabular}{l|l|l|l}
\multicolumn{1}{c|}{ Município } & \multicolumn{1}{c|}{\begin{tabular}{l}
\multicolumn{1}{c}{ PIB } \\
(em milhões)
\end{tabular}} & & \multicolumn{1}{c}{ Renda Médio } \\
\hline Natal & $19.076 .030,47$ & Natal & 921,29 \\
\hline Mossoró & $6.221 .099,05$ & Parnamirim & 833,82 \\
\hline Parnamirim & $4.408 .474,16$ & Caicó & 622,27 \\
\hline São Gonçalo do Amarante & $1.630 .595,15$ & Mossoró & 590,33 \\
\hline Macaíba & $1.358 .253,53$ & Currais Novos & 517,60 \\
\hline Caicó & $930.891,52$ & Pau dos ferros & 499,05 \\
\hline Macau & $914.350,27$ & Tibau do Sul & 466,52 \\
\hline Açu & $890.710,40$ & Macau & 448,18 \\
\hline Areia Branca & $819.391,33$ & Jardim do Seridó & 445,31 \\
\hline Ceará-Mirim & $710.929,04$ & Areia Branca & 445,19 \\
\hline
\end{tabular}

A Tabela 2 apresenta os dados do PIB e da Renda Média dos países mais desenvolvidos, segundo a sua respectiva variável analisada, como forma de facilitar o acompanhamento da discussão sobre os dados apresentados.

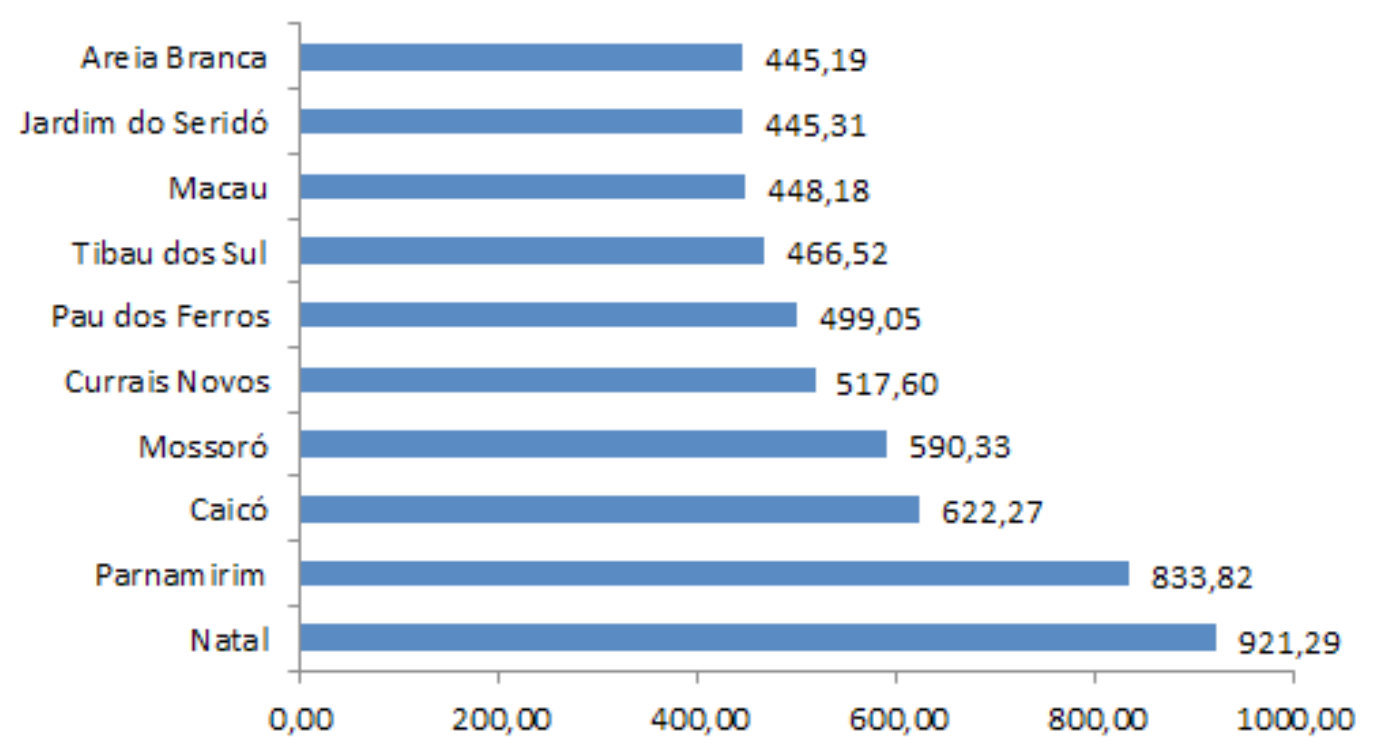

Figura 2: Renda Média domiciliar per capita dos municípios do RN mais desenvolvidos 
Através da Figura 2 percebe-se a disparidade de valores entre a primeira e a décima maior cidade em termos de renda média, Natal $(R \$ 921,29)$ e Areia Branca $(R \$ 445,19)$, diante de seus respectivos dados. Entre as cidades mais desenvolvidas, Natal se apresenta em primeiro lugar tanto em relação ao PIB quanto à renda média domiciliar per capita, enquanto Areia Branca se apresenta na $9^{a}$ colocação em relação ao PIB e em $10^{\text {a }}$ colocação entre os municípios de maior renda média.

Observa-se também que os municípios que se encontra entre a quinta e a décima colocação possuem uma renda média bastante semelhante e com valores bem inferiores em relação aos quatro primeiros colocados. Entre os 167 municípios, Mossoró que se encontra na segunda posição quanto ao seu PIB, a sua renda média comparando-se aos dez municípios mais desenvolvidos lhe atribui à quarta colocação.

Existem muitos municípios em que o Produto Interno Bruto arrecadado não consegue se transformar em parte, em distribuição de renda, como é o caso de São Gonçalo do Amarante e Macaíba, por exemplo, que representam respectivamente o $4^{\circ}$ e $5^{\circ}$ municípios do Estado de acordo com o PIB, mas que em relação à renda média per capita, se encontram respectivamente $27^{\mathrm{a}}$ e $28^{\mathrm{a}}$ posições. 0 caso mais crítico diante desta análise trata-se de Ceará Mirim. 0 município se encontra na $10^{\text {a }}$ colocação entre as cidades mais desenvolvidas, de acordo com o seu PIB, e apenas na $45^{\text {a }}$ colocação em relação à renda média.

Por outro lado, entre os dez melhores municípios em termos de renda média, três merecem destaque diante desta análise: Pau dos Ferros (26 colocação no PIB e $6^{\text {a }}$ colocação na renda média), Tibau do Sul ( $30^{\mathrm{a}}$ colocação no PIB e $7^{\mathrm{a}}$ colocação na renda média per capita); e Jardim do Seridó (50a colocação no PIB e $9^{a}$ colocação na renda média). Dessa forma, conclui-se que não existe uma relação direta entre o Produto Interno Bruto e a renda média per capita destes municípios.

5.3 Estimativa de População dos municípios mais desenvolvidos do RN

Diante dos cálculos entre a relação da Estimativa de População com o PIB dos 167 municípios do RN, percebe-se uma correlação muito forte de 0,9973 . Este índice indica que a estimativa de população de qualquer um dos municípios encontra-se fortemente correlacionada com o valor do seu PIB, representando-se dessa forma um dos motivos de crescimento local com a imigração de pessoas de outras regiões para aquele que representa um PIB maior.

Tabela 3: Produto Interno Bruto versus Estimativa de População dos municípios mais desenvolvidos do RN

\begin{tabular}{l|r|r|r}
\multicolumn{1}{c|}{ Município } & $\begin{array}{c}\text { PIB } \\
\text { (em milhões) }\end{array}$ & Município & $\begin{array}{c}\text { Estimativa de } \\
\text { População }\end{array}$ \\
\hline Natal & $19.076 .030,47$ & Natal & 877.662 \\
\hline Mossoró & $6.221 .099,05$ & Mossoró & 291.937 \\
\hline Parnamirim & $4.408 .474,16$ & Parnamirim & 248.623 \\
\hline São Gonçalo do & & São Gonçalo do & 99.724 \\
\hline Amarante & $1.630 .595,15$ & Amarante & 79.211 \\
\hline
\end{tabular}




\begin{tabular}{l|r|l|l}
\hline Caicó & $930.891,52$ & Ceará Mirim & 73.370 \\
\hline Macau & $914.350,27$ & Caicó & 67.747 \\
\hline Açu & $890.710,40$ & Açu & 57.743 \\
\hline Areia Branca & $819.391,33$ & Currais Novos & 45.060 \\
\hline Ceará-Mirim & $710.929,04$ & São José do Mipibu & 43.598 \\
\hline
\end{tabular}

Fonte: IBGE/IDEMA (2014); IBGE (2016).

Este resultado pode ser avaliado como positivo entre os municípios, uma vez que reflete a distribuição demográfica de acordo com o desenvolvimento local, onde as pessoas buscam por emprego, renda e melhor qualidade de vida. No entanto, esta relação não significa que a estimativa de população segue fielmente o resultado do seu PIB.

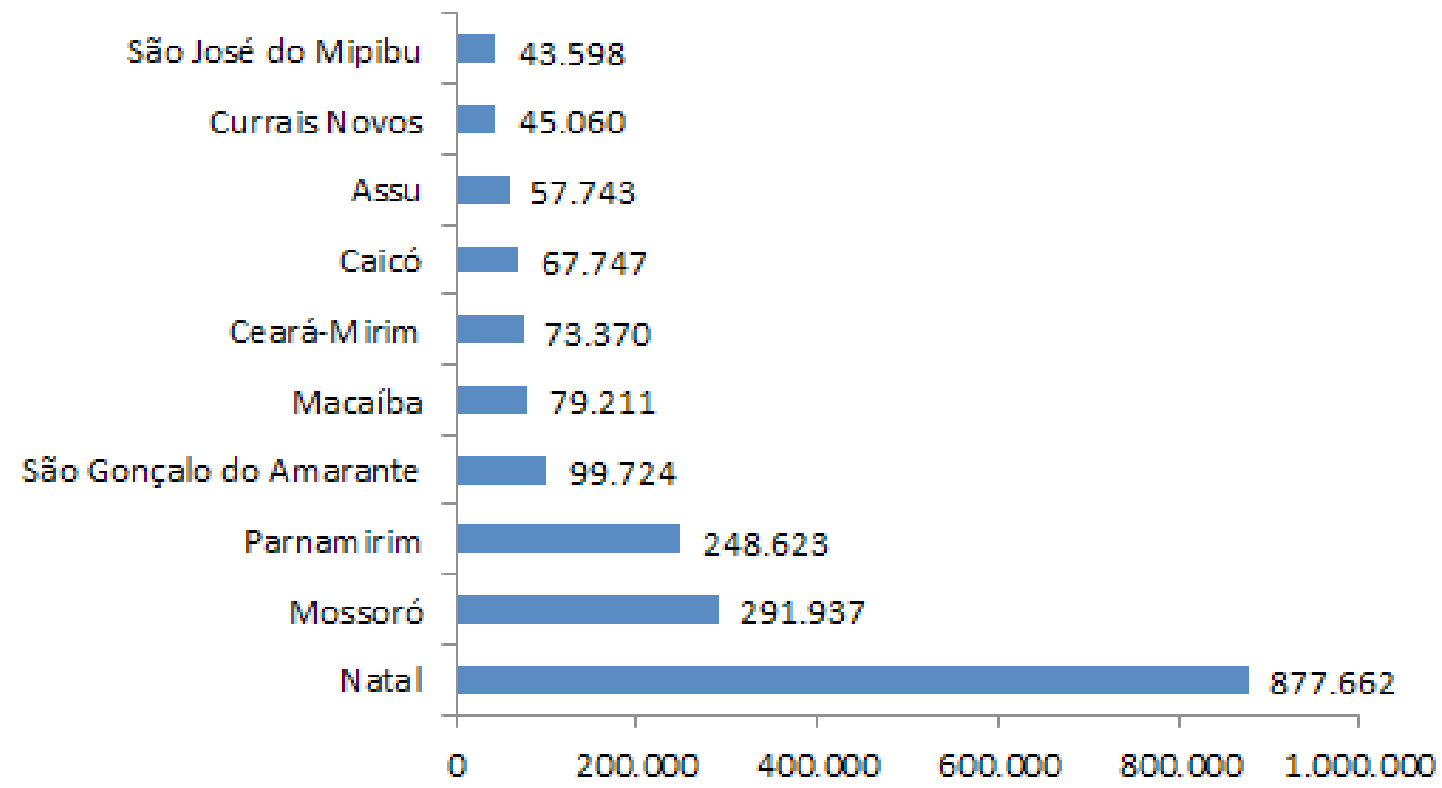

Figura 3: Estimativa de população dos municípios do RN mais desenvolvidos

Nestes casos específicos, observa-se que existe a presença de outros fatores que auxiliam a sua distribuição de renda e que se trata de um fenômeno bastante independente do resultado do produto Interno Bruto destas respectivas cidades. Diante da análise dos dados através da Figura 3, percebe-se uma grande discrepância entre Natal (877.662) e São José do Mipibu (43.598) em relação à Estimativa de População.

Comparando-se apenas entre os 10 municípios mais desenvolvidos, percebe-se que Ceará Mirim, por exemplo, que apresenta apenas a $10^{\mathrm{a}}$ colocação em relação ao PIB e a $45^{\mathrm{a}}$ colocação em relação à renda média per capita, quando se trata de sua estimativa de população, o município se encontra na $6^{\text {a }}$ colocação, apresentando uma estimativa maior que Caicó, Assu, Macau e Areia Branca. Outros municípios que ao menos figuram entre os 10 mais desenvolvidos, acabam fazendo parte deste cenário 
diante da sua estimativa de população, como é o caso de Currais Novos (45.060) e São José de Mipibu (43.598). Se este fosse o principal índice de análise de crescimento e desenvolvimento, estes dois municípios estariam à frente de Macau ( $17^{\mathrm{a}}$ colocação) e Areia Branca (21ª colocação), uma vez que em relação ao PIB estes dois municípios figuram na $9^{\mathrm{a}}$ e $10^{\mathrm{a}}$ posição respectivamente.

\subsection{IDH Médio dos municípios mais desenvolvidos do RN}

Tabela 4: Produto Interno Bruto versus IDH médio dos municípios mais desenvolvidos do RN

\begin{tabular}{l|r|l|r}
\multicolumn{1}{c|}{ Município } & \multicolumn{1}{c|}{$\begin{array}{c}\text { PIB } \\
\text { (em milhões) }\end{array}$} & Município & IDH médio \\
\hline Natal & $19.076 .030,47$ & Parnamirim & 0,766 \\
\hline Mossoró & $6.221 .099,05$ & Natal & 0,763 \\
\hline Parnamirim & $4.408 .474,16$ & Mossoró & 0,720 \\
\hline São Gonçalo do & & Caicó & 0,710 \\
Amarante & $1.630 .595,15$ & & 0.694 \\
\hline Macaíba & $1.358 .253,53$ & São José do Seridó & 0,691 \\
\hline Caicó & $930.891,52$ & Currais Novos & 0,682 \\
\hline Macau & $914.350,27$ & Areia Branca & 0,679 \\
\hline Açu & $890.710,40$ & Ipueira & 0,679 \\
\hline Areia Branca & $819.391,33$ & Acari & 0,678 \\
\hline Ceará-Mirim & $710.929,04$ & Pau dos Ferros & \\
\hline
\end{tabular}

Fonte: IBGE/IDEMA (2014); IBGE (2016).

Os dados apresentados pela Tabela 4 demonstra a relação existente entre o valor do PIB e o IDH Médio dos municípios mais desenvolvidos, destacando um grande desencontro entre aqueles municípios considerados como os mais desenvolvidos, segundo o seu PIB per capita em comparação com os melhores municípios diante do resultado apresentado pelo seu IDH. 


\section{ISSN - 2447-178X}

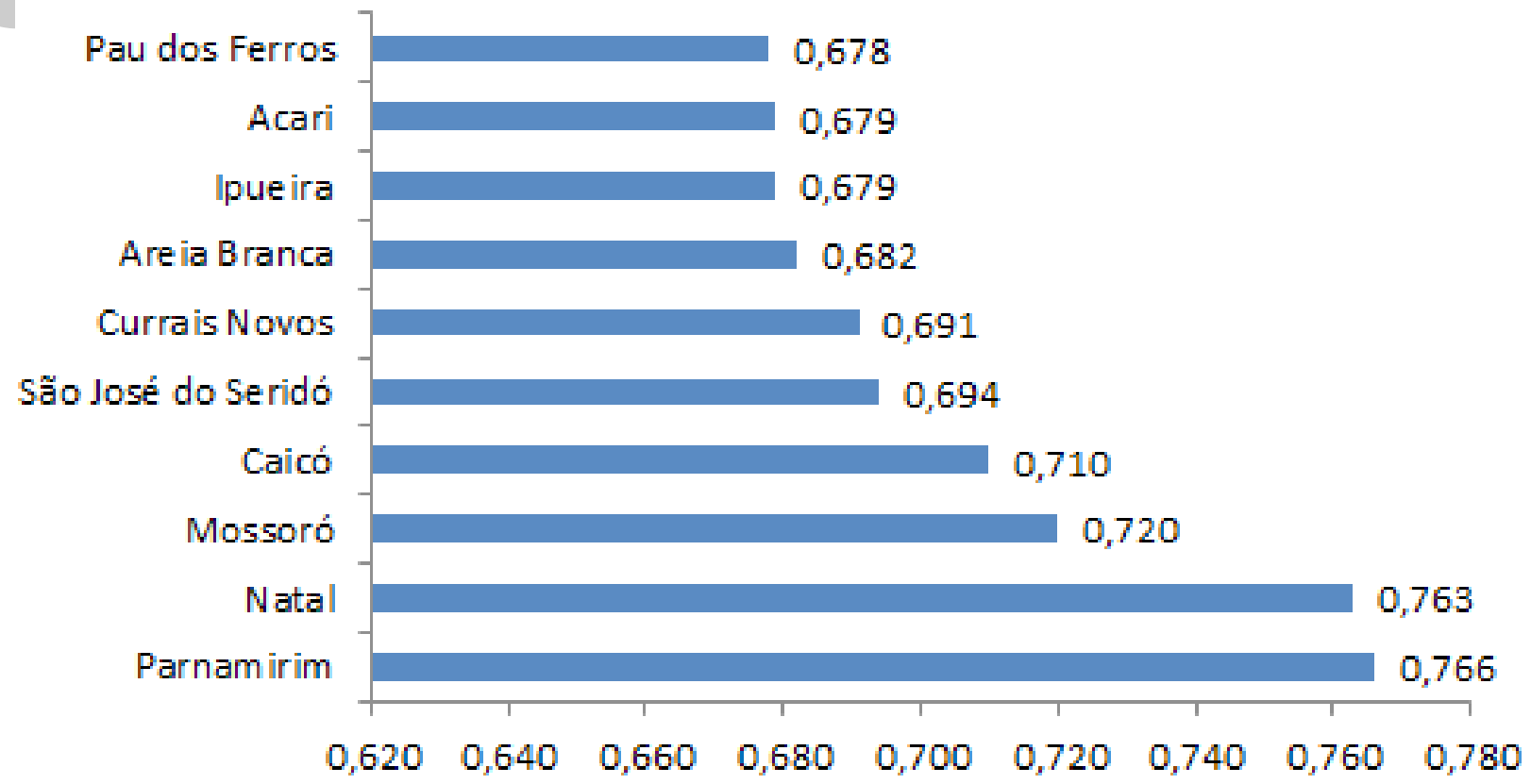

Figura 4: índice de Desenvolvimento Humano dos municípios do RN mais desenvolvidos

De acordo com os dados apresentados no Gráfico 4, percebe-se que dos 167 municípios do Rio Grande do Norte, apenas quatro possuem IDH alto (de 0,700 a 0,799) e que da $5^{\mathrm{a}}$ a $10^{\mathrm{a}}$ colocação, todos os municípios encontram-se classificados como IDH médio (de 0,600 a 0,699). Ao todo, o Estado possui 93 municípios com IDH médio, o que significa que a maioria dos municípios precisam se desenvolver mais. Vale salientar que este índice é calculado segundo o IDH de outras variantes, tais como: longevidade, renda e educação, criando-se a partir de seus resultados o IDH médio.

0 município de Ipueira que se encontra na $163^{a}$ posição em relação ao $\mathrm{PIB}$, possui o $8^{\circ}$ maior IDH dos 167 municípios, assim como São José do Seridó, 93a posição no PIB, apresenta o $5^{\circ}$ melhor IDH. A própria capital do Estado, Natal que representa o maior PIB, encontra-se em $3^{\text {a }}$ lugar abaixo de Parnamirim e Mossoró, respectivamente. No entanto, estes últimos dados podem ser considerados como normais ou esperados, uma vez que entre os municípios mais desenvolvidos não se observam uma disparidade muito grande de colocação entre uma variável analisada e outra. Muitas pessoas residem nos municípios adjacentes e preferem trabalhar em Natal, diante de uma demanda maior por oportunidades de trabalho e de possibilidades de melhores salários.

\subsection{Produto Interno Bruto dos municípios menos desenvolvidos do RN}

Em relação aos municípios menos desenvolvidos, alguns apresentam dados bastante significativos para este estudo, por contrariarem a lógica esperada em relação às variáveis analisadas, como é o caso de Ipueira, que apresenta apenas a $163^{\mathrm{a}}$ colocação em relação ao PIB, a $165^{\mathrm{a}}$ colocação em termos de Estimativa de População, mas que apresenta a seu favor o $8^{\circ}$ IDH Médio entre os 167 municípios e a $18^{\mathrm{a}}$ posição em relação à Renda Média. No entanto, quando se observa o seu PIB per capita, a sua colocação passa a ser a $66^{a}$ posição, de acordo com os seus dados coletados em 2014. Outra particularidade deste município é que $97 \%$ de todas as suas receitas são oriundas de fontes externas, 0 


\section{ISSN - 2447-178X}

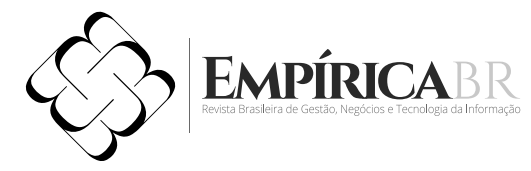

que se configura em mais um desafio para o município. Talvez um dos índices que possibilita o seu IDH médio, é a observação de que 98,1\% de todas as suas crianças com idade entre 6 e 14 anos de idade encontram-se matriculados nas escolas e apresentar um índice 0 de mortalidade infantil por cada mil crianças nascidas vivas. Mesmo não possuindo as condições ideais de salários, por exemplo, existe um bom investimento em saúde e educação nesta cidade, apresentando inclusive três Estabelecimentos de Saúde do SUS na cidade.

Tabela 5: Produto Interno Bruto dos municípios menos desenvolvidos do RN
\begin{tabular}{l|l}
\multicolumn{1}{c|}{ Município } & \multicolumn{1}{c}{ PIB (em milhões) } \\
\hline Fernando Pedroza & $24.716,45$ \\
\hline Rafael Godeiro & $22.329,08$ \\
\hline Água Nova & $21.623,29$ \\
\hline Taboleiro Grande & $20.571,70$ \\
\hline Pedra Preta & $20.418,43$ \\
\hline Ipueira & $20.154,24$ \\
\hline Jardim de Angicos & $19.950,84$ \\
\hline Monte das Gameleiras & $19.690,41$ \\
\hline João Dias & $18.606,80$ \\
\hline Viçosa & $13.106,84$
\end{tabular}

Fonte: IBGE/IDEMA (2014).

De acordo com os dados da Tabela 5, percebe-se que o PIB é bastante inferior em relação aos municípios mais desenvolvidos, atingindo apenas a casa de dezenas de milhares. Estes municípios sobrevivem apenas com atividades administrativas ligadas diretamente ao exercício da gestão pública municipal, seja como funcionários públicos ou prestadores de serviços, e não possuem uma atividade produtiva que lhe garanta uma distribuição de renda mais elevada. No entanto, vale salientar que estes municípios encontram-se nas últimas colocações apenas em relação ao seu PIB. Quando se trata das demais variáveis analisadas, percebe-se que muitos apresentam qualidade de vida ou desempenho que os colocam em posições bastante representativas entre os 167 municípios do Rio Grande do Norte, como será analisado nos próximos gráficos.

Alguns dados comprovam não existir nenhuma relação entre o PIB apresentado na Tabela 5, e o IDH médio, por exemplo, como é o caso de Ipueira, que apresenta o $163^{\circ}$ pior PIB entre os municípios menos desenvolvidos e se encontra na $8^{a}$ colocação diante do seu IDH médio. 


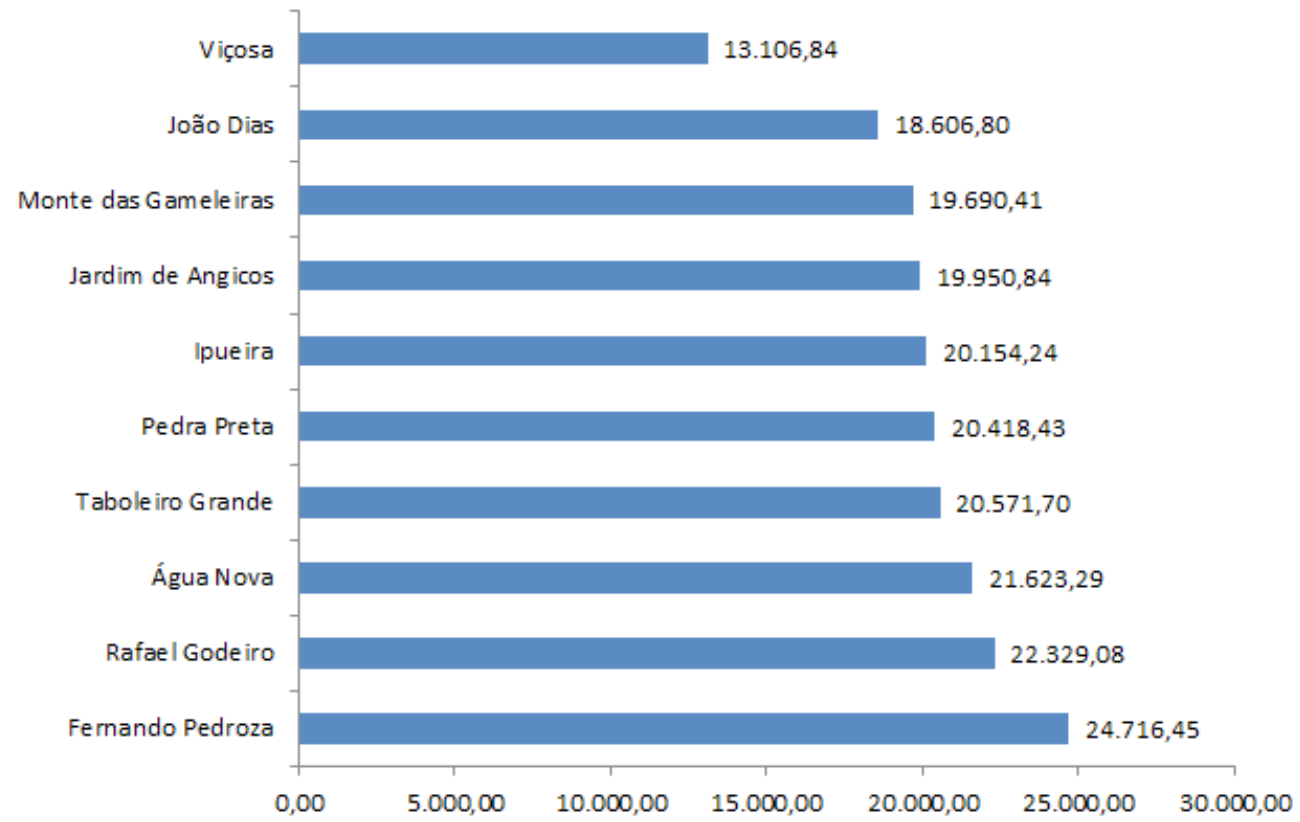

Figura 5: Produto Interno Bruto (em milhões) dos municípios do RN menos desenvolvidos

Observando-se a cidade de Viçosa, que apresenta o pior resultado do PIB entre os 167 municípios, percebese que apenas $12,5 \%$ da população representa a população ocupada e que ganha em média 1,6 salários mínimos, enquanto $53,5 \%$ da população possui um rendimento nominal mensal per capita de até 0,5 salários mínimos. De acordo com os dados do IBGE, este município não possui receitas oriundas de fontes externas. Com exceção de Viçosa, observa-se um equilíbrio entre o PIB apresentado pelos demais municípios da Figura 5, principalmente entre os municípios que se encontram no intervalo entre o quarto e o nono colocado (IBGE, 2016).

\subsection{Renda Média dos municípios menos desenvolvidos do RN}

Tabela 6: Produto Interno Bruto versus Renda Média dos municípios menos desenvolvidos do RN

\begin{tabular}{l|r|r|r}
\multicolumn{1}{c|}{ Município } & \multicolumn{1}{c|}{ PIB } & Município & Renda Média \\
\hline Fernando Pedroza & $24.716,45$ & Japi & 211,63 \\
\hline Rafael Godeiro & $22.329,08$ & São Bento do Trairi & 208,00 \\
\hline Água Nova & $21.623,29$ & Pedra Grande & 206,95 \\
\hline Taboleiro Grande & $20.571,70$ & Água Nova & 205,55 \\
\hline Pedra Preta & $20.418,43$ & Senador Elói de Souza & 203,09 \\
\hline Ipueira & $20.154,24$ & lelmo Marinho & 202,40 \\
\hline Jardim de Angicos & $19.950,84$ & Pureza & 193,38 \\
\hline Monte das Gameleiras & $19.690,41$ & Januário Cicco & 189,97 \\
\hline João Dias & $18.606,80$ & Venha-Ver & 177,88 \\
\hline Viçosa & $13.106,84$ & João Dias & 169,91 \\
\hline
\end{tabular}

Fonte: IBGE/IDEMA (2014); DATASUS (2010). 


\section{ISSN - 2447-178X}

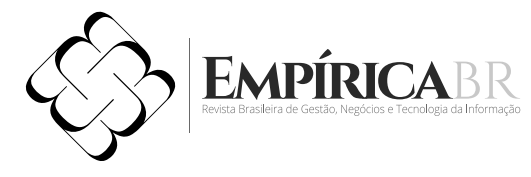

Na Tabela 6 observa-se a relação entre o PIB e a Renda Média dos municípios menos desenvolvidos e estes respectivos dados demonstram que não existe uma correlação muito forte entre estas duas variantes. Comparando-se estas duas variantes, apenas os municípios de Água Nova e João Dias são mencionados nos dados das duas variantes.

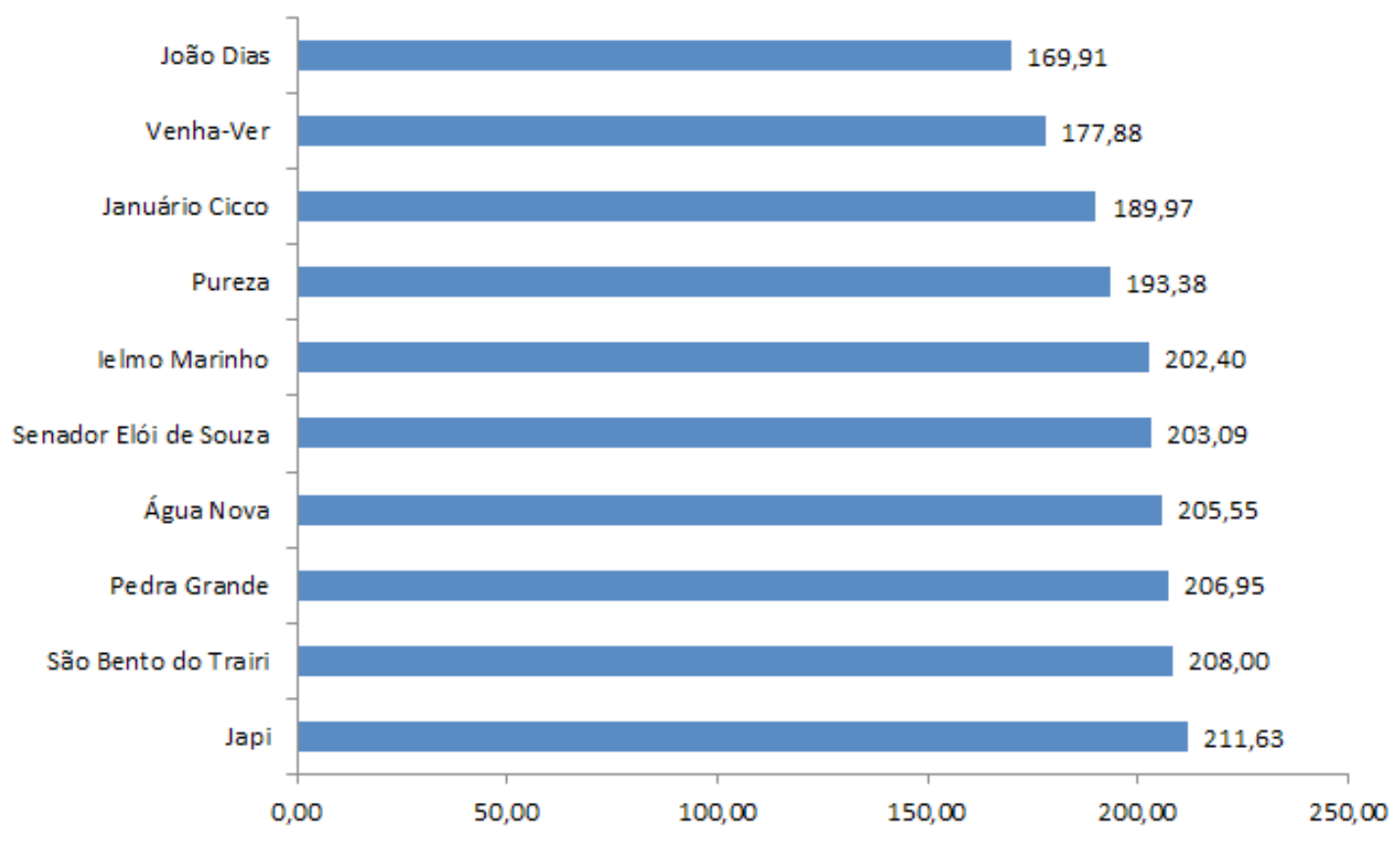

Figura 6: Renda Média domiciliar per capita dos municípios do RN menos desenvolvidos

Comparando-se os dados apresentados no Gráfico $6 \mathrm{com}$ os respectivos valores destes mesmos municípios em relação ao seu PIB, observa-se um fato bastante curioso. Entre estes 10 municípios, apenas 2 se encontram entre os municípios que apresentam os menores valores para o seu respectivo

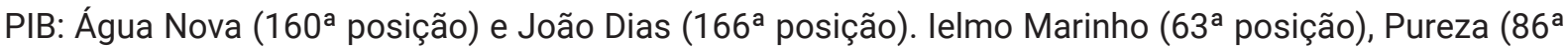
posição) e Januário Cicco ( $90^{\mathrm{a}}$ posição) apresentam posições mais confortáveis em relação ao PIB, demonstrando-se dessa forma que não existe uma correlação expressiva entre o seu PIB e a Renda Média per capita de cada município. Diante deste gráfico, observa-se também que estes municípios sobrevivem em questão de vulnerabilidade social e que necessita de uma atenção especial por parte de esferas superiores de Governo, seja através da estância Estadual ou Federal, uma vez que a Renda Média não apresenta sequer um terço do salário mínimo vigente.

Para estes municípios, buscar soluções apenas sob a instância municipal seria algo praticamente impossível de ser pensado. Trata-se de municípios que necessitam de apoio por parte do Governo Federal e Estadual, que permitam potencializar a capacidade produtiva de cada município, além de possibilitar a geração de emprego e renda destes municípios.

\subsection{Estimativa de População dos municípios menos desenvolvidos do RN}

A Tabela 7 apresenta a relação entre os municípios que apresentam o menor PIB e a menor Estimativa de População, respectivamente. Diante dos dados apresentados, percebe-se que a maioria 
das cidades com o PIB mais baixo do Estado também se configuram como aqueles que possuem a menor Estimativa de População, com exceção de apenas 4 municípios.

Tabela 7: Produto Interno Bruto versus Estimativa de População dos municípios menos desenvolvidos do RN

\begin{tabular}{l|r|c|r}
\hline \multicolumn{1}{c|}{ Município } & $\begin{array}{c}\text { PIB } \\
\text { (em milhões) }\end{array}$ & Município & $\begin{array}{r}\text { Estimativa } \\
\text { de População }\end{array}$ \\
\hline Fernando Pedroza & $24.716,45$ & Santana do Seridó & 2.688 \\
\hline Rafael Godeiro & $22.329,08$ & Jardim de Angicos & 2.666 \\
\hline Água Nova & $21.623,29$ & Galinhos & 2.650 \\
\hline Tabuleiro Grande & $20.571,70$ & Pedra Preta & 2.550 \\
\hline Pedra Preta & $20.418,43$ & Tabuleiro Grande & 2.542 \\
\hline & & Timbaúba & 2.428 \\
\hline Ipueira & $20.154,24$ & Batistas & 2.332 \\
\hline Jardim de Angicos & $19.950,84$ & Bodó & 2.236 \\
\hline Monte das Gameleiras & $19.690,41$ & Ipueira & 2.198 \\
\hline João Dias & $18.606,80$ & Monte das Gameleiras & 1.722 \\
\hline Viçosa & $13.106,84$ & Viçosa & \\
\hline
\end{tabular}

Fonte: IBGE/IDEMA (2014); IBGE (2016).

Quando se trata da estimativa de população, percebe-se através da Figura 7 que os dados apresentados possuem uma grande correlação com o resultado do PIB destes referidos municípios, observando-se apenas algumas exceções.

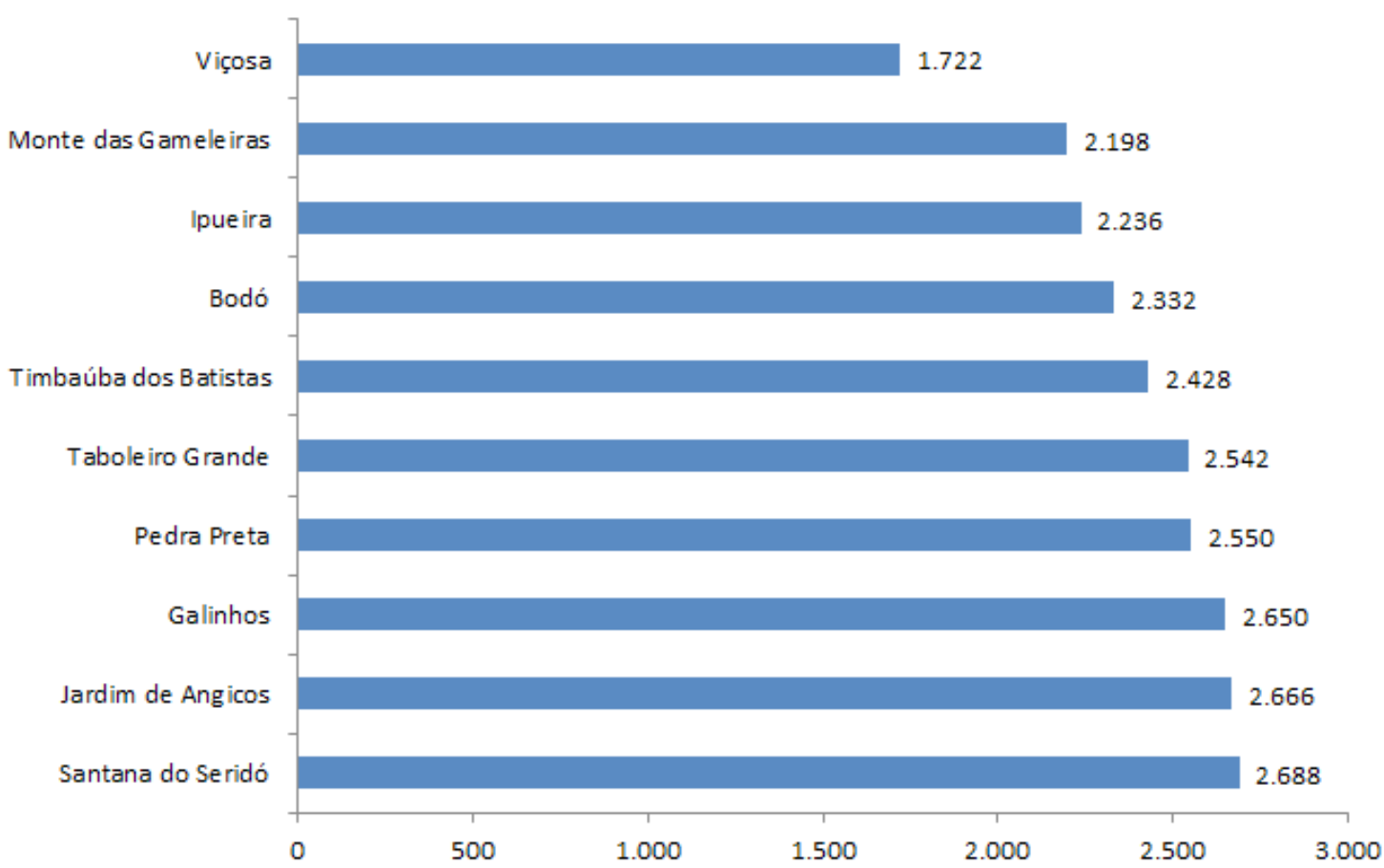

Figura 7: Estimativa de população dos municípios do RN menos desenvolvidos 
Entre todos os municípios observados na Figura 7, percebe-se que Jardim de Angicos, Pedra Preta, Taboleiro Grande, Ipueira, Monte das Gameleiras e Viçosa também se encontram entre os municípios menos desenvolvidos em relação aos seus respectivos valores do PIB, seguido de Timbaúba dos Batistas que apresenta o $157^{\circ} \mathrm{PIB}$, isto é, possuindo a $11^{\text {a }}$ colocação entre os municípios menos desenvolvidos. Alguns dos municípios apresentados na Figura 7 que não apresentam uma representativa correlação entre a sua estimativa de população e seu respectivo PIB, isto é, comparando-se com os demais municípios, a sua estimativa de população apresenta um crescimento inferior aos resultados apresentados pelo respectivo PIB de cada município, acabam sendo beneficiados por uma renda média mais expressiva.

Por outro lado, os municípios menos desenvolvidos em relação a esta variável não possuem quase nenhuma correlação com os municípios que apresentam os menores valores de Renda Média per capita. Santana do Seridó que se encontra na $158^{\mathrm{a}}$ posição em relação a sua estimativa de população, possui o $136^{\circ}$ PIB e a $9^{\text {a }}$ Renda Média per capita dos 167 municípios estudados. Ipueira por sua vez, possui a $165^{\text {a }}$ estimativa de população e o $163^{\circ} \mathrm{PIB}$, no entanto, se encontra na $18^{\mathrm{a}}$ posição quando se trata da sua Renda Média. Em seguida, observa-se os dados apresentados pelo município de Bodó, que se encontra na $164^{a}$ posição em relação a estimativa de população, mas que apresenta um certo equilíbrio quando se trata do PIB (70ª posição) e da sua Renda Média ( $92^{\mathrm{a}}$ posição).

\subsection{IDH Médio dos municípios menos desenvolvimento do RN}

Finalmente na Tabela 8 observa-se a relação entre o PIB e o IDH médio dos municípios menos desenvolvidos do RN e as suas possíveis correlações. De todas as variantes, esta pode ser considerada como a mais complexa de se analisar as condições de crescimento e desenvolvimento de um determinado município, diante de vários fatores difíceis de serem comparados entre municípios, como é a questão da longevidade, da renda e da educação trabalhados nesta variante.

Tabela 8: Produto Interno Bruto versus IDH médio dos municípios menos desenvolvidos do RN

\begin{tabular}{l|r|l|r}
\hline \multicolumn{1}{c|}{ Município } & $\begin{array}{c}\text { PIB } \\
\text { (em milhões) }\end{array}$ & \multicolumn{1}{c}{ Município } & IDH médio \\
\hline Fernando Pedroza & $24.716,45$ & Pedra Grande & 0,559 \\
\hline Rafael Godeiro & $22.329,08$ & Pedra Preta & 0,558 \\
\hline Água Nova & $21.623,29$ & Espírito Santo & 0,558 \\
\hline Tabuleiro Grande & $20.571,70$ & Montanhas & 0,557 \\
\hline Pedra Preta & $20.418,43$ & Venha-Ver & 0,555 \\
\hline Ipueira & $20.154,24$ & São Bento do Norte & 0,555 \\
\hline Jardim de Angicos & $19.950,84$ & Lagoa de Pedras & 0,553 \\
\hline Monte das Gameleiras & $19.690,41$ & lelmo Marinho & 0,550 \\
\hline João Dias & $18.606,80$ & Parazinho & 0,549 \\
\hline Viçosa & $13.106,84$ & João Dias & 0,530 \\
\hline
\end{tabular}

Fonte: IBGE/IDEMA (2014); IBGE (2016). 


\section{ISSN - 2447-178X}

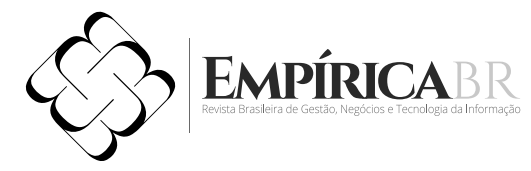

Entre os municípios classificados como menos desenvolvidos diante do seu resultado do PIB, apenas dois configuram-se entre aqueles que possuem o IDH mais baixo. Mesmo diante desta mínima correlação entre estas duas variantes, não se pode afirmar que o IDH médio não serve como variante de análise sobre o crescimento e desenvolvimento. Talvez seja mais sensato afirmar que o IDH médio isolado não deve ser considerado como elemento classificador de desenvolvimento, da mesma forma que aqueles que possuem os melhores valores do PIB são os municípios que apresenta melhor qualidade de vida. Por outro lado, uma pequena cidade é mais fácil de gerir as questões de educação e saúde do que uma cidade maior e mais desenvolvida.

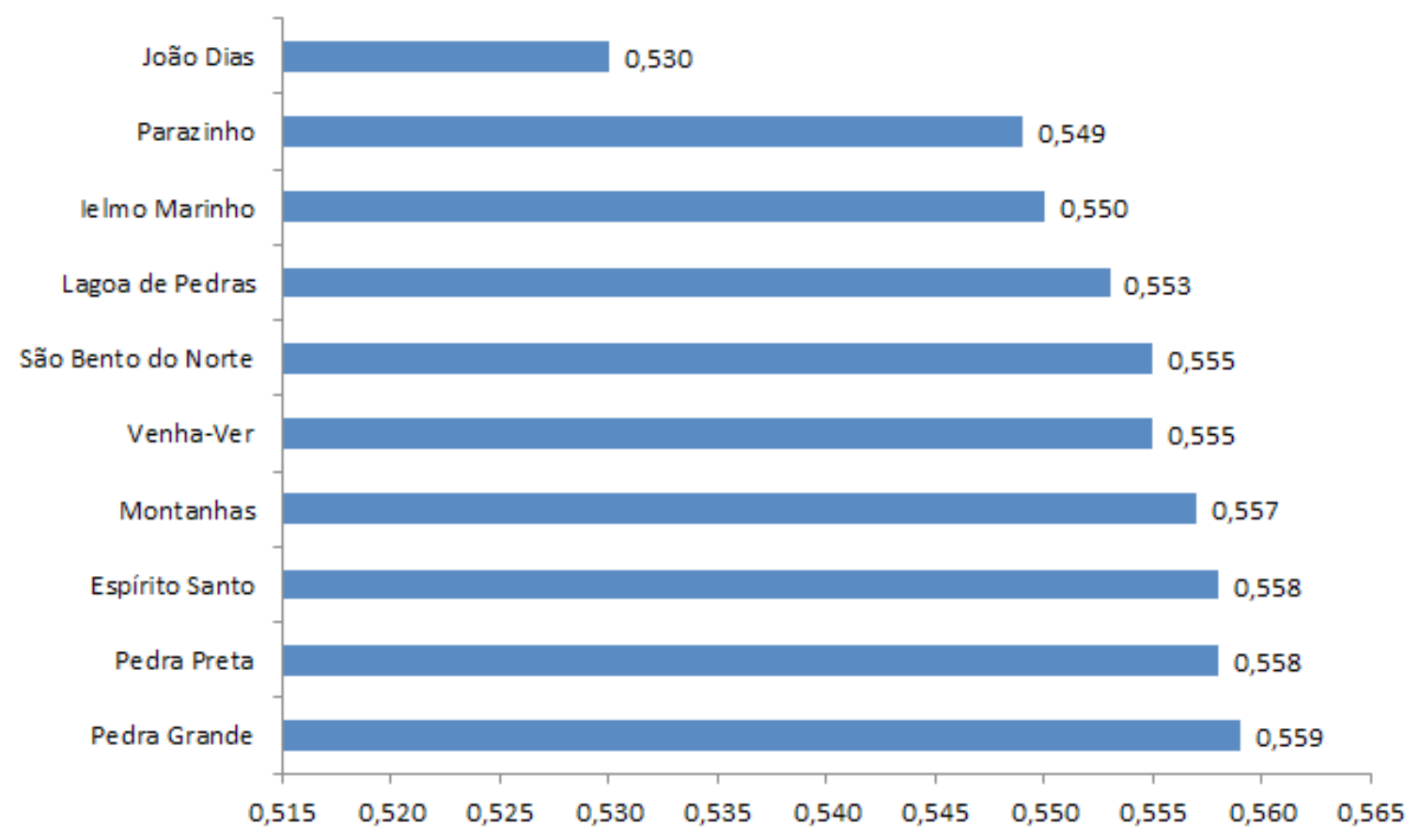

Figura 8: IDH médio dos municípios do RN menos desenvolvidos

Neste último gráfico, observa-se os dados apresentados pela variável mais sensível de ser analisada, quando o assunto é crescimento e desenvolvimento. Para chegar a estes dados de IDH médio, necessita-se calcular a média entre os IDH de longevidade, renda e educação e, dessa forma, nem sempre os municípios mais desenvolvidos em relação ao PIB são aqueles que representam o IDH mais alto. Como já foi observado na Figura 7 que a maioria dos municípios possuem uma alta correlação entre PIB e estimativa de população, para o Gráfico 8 será realizada uma comparação entre IDH, PIB e Renda Média per capita.

De acordo com os valores apresentados, com exceção de apenas alguns municípios, todos os demais apresentam uma correlação entre IDH, PIB e Renda Média ou IDH e Renda Média. Parazinho, por exemplo, que possui o $166^{\circ} \mathrm{IDH}$ mais baixo entre todos os municípios do Estado do RN, encontrase na $33^{\mathrm{a}}$ posição em relação ao seu PIB e $146^{\mathrm{a}}$ posição quando se trata de Renda Média per capita. Além deste município, apenas Espírito Santo ( $145^{\mathrm{a}}$ colocação em relação ao PIB) e Montanhas (130 colocação em relação ao PIB) se encontram com valores de PIB inferiores a $150^{\text {a }}$ colocação. Este 


\section{ISSN - 2447-178X}

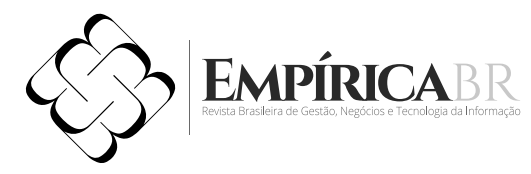

resultado demonstra que o IDH encontra-se bastante correlacionado com a questão da Renda Média per capita e apresentam uma correlação média com o PIB. Uma das questões a ser respondida neste contexto, é o caso do município de Parazinho que ocupa a penúltima colocação em relação ao IDH médio dos municípios, quando na verdade o seu PIB o coloca na $33^{\text {a }}$ posição, próxima dos municípios mais desenvolvidos em relação ao PIB.

Observando-se os dados de todos os municípios analisados segundo cada variável estudada, percebe-se que dos 167 municípios do Estado do RN, apenas 4 entre os mais desenvolvidos configuram sua posição entre os municípios mais desenvolvidos em todos os quesitos, que são: Natal, Parnamirim, Mossoró e Caicó. Na outra margem, apenas João Dias se encontra entre os 10 municípios menos desenvolvidos diante das variáveis PIB, Renda Média per capita e IDH, e na $157^{a}$ posição (11 a posição entre os menos desenvolvidos) diante da sua estimativa de população.

Outro dado interessante é que entre as quatro variáveis de crescimento e desenvolvimento analisadas, comparando-se as dez cidades mais desenvolvidas e as dez menos desenvolvidas, observa-se a movimentação de 19 municípios entre os mais desenvolvidos, enquanto entre os menos desenvolvidos, foram analisados dados de 27 municípios.

Outra observação que poderá ser feita a partir da tabela 2 diz respeito ao IDH médio destes respectivos municípios. Como eles são considerados como os menos desenvolvidos segundo o seu PIB, seria normal esperar que os mesmos apresentassem IDH médio inferiores aos demais municípios, o que na realidade, não acontece e tais observações servem para justificar a relevância deste tipo de pesquisa.

\section{DISCUSSÃO}

De acordo com as principais fontes utilizadas, percebe-se que todas as variantes foram formadas através de dados e informações coletados em anos diferentes. O PIB utilizado para efeito de análise foi apresentado pelo IBGE em 2014, a Estimativa de População se refere aos dados de 2016, a Renda Média foi divulgada pela DATASUS em 2010 e o IDH médio, mesmo divulgado em 2013, trata-se do censo realizado também em 2010. No entanto, estes dados refletem a realidade do Estado do Rio Grande do Norte uma vez que as suas atividades econômicas e índices de crescimento demográfico acontecem de uma forma linear, porém sem muitas discrepâncias em relação às atividades e fenômenos ocorridos neste contexto.

De acordo com o Sistema FIERN (2014), o desenvolvimento de um determinado território, seja este um país ou um Estado da federação, não pode ser confundido com o crescimento econômico, muito menos limitado à produção de riqueza, com base nas suas potencialidades, e tal afirmação pode ser comprovada nas análises realizadas no capítulo anterior. Para compreender a questão do desenvolvimento do Rio Grande do Norte, deve-se observar o aumento continuado das vantagens competitivas da sua economia, no entanto tendo a consciência de que nenhum território pode ou deve pretender ser competitivo em tudo. 0 que se espera é que os seus gestores procurem construir condições gerais de competitividades que possam favorecer as atividades econômicas em que cada município possa se diferenciar no mercado global. 


\section{ISSN - 2447-178X}

Entre os municípios que apresentam maiores índices de desenvolvimento econômico, percebe-se que existe uma forte relação entre o PIB e a Estimativa de População, o que caracteriza a dinâmica da economia e a distribuição de potencialidades econômica destes municípios. Neste contexto, também se torna visível as oportunidades de emprego que decorrem dos investimentos realizados nestes municípios, relacionados ao turismo, fruticultura, petróleo e gás, indústria salineira, entre outros. Nos últimos anos, observa-se algumas mudanças de cenários econômicos em deslocamento no Estado do Rio Grande do Norte, como por exemplo, a construção do novo Aeroporto Internacional de São Gonçalo do Amarante e as atividades ampliadas pela Zona de Processamento de Exportações (ZPE) em Macaíba. Estas mudanças passam a ser perceptíveis quando analisamos cada variável e observamos, entre os municípios mais desenvolvidos, como se comportam os seus posicionamentos diante do PIB, da Estimativa de População e da Renda Média per capita.

Um dos exemplos a ser citado se trata do município de Parnamirim, que a cada dia diminui o seu ritmo de crescimento e desenvolvimento após a perda do Aeroporto e das demais atividades aeroportuária para o município de São Gonçalo do Amarante. No entanto, mesmo com esta perspectiva para o futuro, de acordo com os dados do Sistema FIERN (2014), a projeção por tendência da população de Parnamirim para o ano de 2034 é a sua ascensão do terceiro município mais populoso do Estado para a segunda colocação, ultrapassando o município de Mossoró, que hoje ocupa a segunda colocação. No entanto, ainda segundo a estimativa de população, entre os demais municípios mais desenvolvidos até a $10^{\mathrm{a}}$ colocação, os dados estatísticos revelam que todos os municípios continuarão a assumir suas respectivas posições, havendo apenas mais uma troca de posição entre Currais Novos ( $9^{a}$ posição) e São José de Mipibu (10ª posição).

Quando comparado com os dois municípios com menor renda média, Venha-Ver (R\$223,27) e João Dias (R\$ 197,00) observa-se que existe uma discrepância acentuada de valores entre os municípios mais desenvolvidos, além de uma concentração de cidades carentes de recursos como forma de investimentos em sua infraestrutura, por não ter condições de oferecer muitas opções de crescimento e desenvolvimento local. Muitos desses municípios vivem exclusivamente da pesca e de atividades ligadas diretamente ao campo, possuindo fontes escassas de recursos e investimentos.

Para aqueles municípios em que o seu desenvolvimento econômico encontra-se diretamente relacionado com o solo e as condições climáticas, tais fenômenos auxiliam na explicação da dinamicidade de seus dados estatísticos. 0 Rio Grande do Norte é cortado por 14 bacias hidrográficas, sendo as maiores as bacias do dos rios Apodi/Mossoró, Piranhas, Ceará-Mirim, Potengi e Trairi que são responsáveis por alimentarem vários açudes e barragens em todo o Estado. No entanto, o baixo desenvolvimento econômico de diversos municípios que fazem parte do contexto geográfico de muitas dessas bacias hidrográficas reflete o problema do convívio com as fortes restrições hídricas, irregularidades pluviométricas que ocasionam ciclos de estiagem grave, além da seca, comprometendo não apenas a qualidade de vida destes municípios, como também, as suas atividades econômicas como é o caso das atividades agropecuárias.

As atividades agrícolas com irrigação moderna se concentram nas duas maiores bacias: na dos rios Apodi e Mossoró que contam com açudes e grande volume de água subterrânea, e na Bacia do rio 


\section{ISSN - 2447-178X}

Piranhas, alimentada apenas por açudes. Mesmo diante deste fator contribuinte para o desenvolvimento local, dependendo da extensão e da intensidade, estas regiões costumam sofrer várias restrições à produção da fruticultura irrigada durante os períodos de estiagem. Este tipo de atividade se concentra principalmente entre os municípios de Mossoró e adjacências, indo até próximo a Assú e se estendendo ao sul no sentido de Pau dos Ferros (SISTEMA FIERN, 2014).

De acordo com o Censo Agropecuário realizado pelo IBGE e publicado em 2006, os municípios que fazem parte da área produtora de frutas tropicais e que se encontram situados nos vales dos rios Piranha-Assu e Apodi-Mossoró são: Alto dos Rodrigues, Baraúna, Tibau, Ipanguaçu, Açu, Apodi, Carnaubais e Mossoró. No entanto, fora deste recorte geográfico também podemos citar os municípios de Arês, Ceará-Mirim, São José do Mipibu, Caicó, Touros, Macaíba e Jardim de Piranhas. Nesses municípios se destacam principalmente a produção de melão, banana, manga, melancia, mamão entre outras espécies de frutas tropicais. (IBGE, 2006).

Entre as atividades relacionadas aos recursos minerais, observa-se que o estado do Rio Grande do Norte possui muitas reservas de minerais metálicos (tungstênio e ferro, por exemplo) e não metálicos (calcário, feldspato e argila), além das grandes reservas de sal. As principais reservas de minérios metálicos encontram-se concentradas principalmente nas Serras Centrais, Caicó e Currais Novos. Os municípios responsáveis pela extração das reservas de ferro são: Jucurutu, Assú, Cruzeta, Ouro Branco, Ipueira, São Rafael e Lajes, enquanto as reservas de tungstênio se concentram nos municípios de Currais Novos Acari, Jucurutu, Parelhas, Assú, Lajes, Pedro Avelino, Bodó e Jardim de Piranhas.

Em se tratando de minerais não metálicos, os municípios com reservas de argila são: Mossoró, Assú, Ipanguaçu, Itajá, Macaíba, São Gonçalo do Amarante, Parelhas, Carnaúba dos Dantas, Acari, Currais Novos, Apodi, São José do Mipibu, Goianinha e Canguaretama. As reservas de calcário encontram-se concentradas nos seguintes municípios: Mossoró, Baraúna, Governador Dix-Sept-Rosado, Lages, Jardim do Seridó, Currais Novos, Assú, Apodi, Felipe Guerra, Jandaíra, Macau e Pendências. O feldspato, por sua vez, é extraído nos municípios de Alexandria, Parelhas, Currais Novos, Equador, Santana do Seridó e Lajes Pintada. Finalmente, as reservas de sal marinho se concentram nos municípios de Macau, Mossoró, Areia Branca, Grossos e Galinhos.

Também se destaca no Estado do Rio grande do Norte a produção de petróleo e gás natural e a sua bacia petrolífera dispõe de produção tanto em terra quanto no Oceano Atlântico, com significativo número de poços produtores principalmente em terra. A produção gerada no Rio grande do Norte destina-se para o abastecimento do próprio Estado, como também, parte da sua produção é destinada para os estados da Paraíba, do Ceará e de Pernambuco. Os poços encontram-se concentrados em Guamaré, parte do Vale do Açu e Vale do Apodi-Mossoró (AZEVEDO, 2013).

Todas estas informações complementares esplanadas neste capítulo servem para ilustrar o comportamento do crescimento e desenvolvimento dos municípios no estado do Rio Grande do Norte, sendo necessário salientar que ainda existem outros tipos de produtividade econômica no estado, como por exemplo, a indústria têxtil, o artesanato, o cultivo do algodão e da cana-de-açúcar, entre outros. Todos estes dados e informações servem para confirmar a importância de um olhar mais apurado sobre a questão de se classificar os municípios mais desenvolvidos do estado, quando na 
verdade, percebe-se que apenas o PIB não pode ser considerado como principal variável de crescimento e desenvolvimento local.

\section{CONCLUSÃO}

Diante do exposto, percebe-se que o Rio Grande do Norte possui um grande potencial de crescimento e desenvolvimento local, concentrado em pequenos nichos ligados diretamente aos setores da indústria, do turismo, extração (mineral, sal e petróleo) e importação. A disparidade apresentada entre o Produto Interno Bruto e a Renda Média de seus municípios, trata-se de uma realidade verificada principalmente pela falta de infraestrutura adequada a praticamente $90 \%$ dos municípios, impossibilitando um desenvolvimento local equilibrado. Por outro lado, entre as cidades mais desenvolvidas em relação ao PIB existem aquelas que não apresentam a mesma escala de desenvolvimento comparado com a sua Estimativa de População e Renda Média. Nestes casos, uma parcela das oportunidades de trabalho oferecidas nestes municípios são efetivadas por profissionais que residem em cidades vizinhas, como pro exemplo, empresas localizadas em Macaíba com parte de seus funcionários residindo em Natal e Parnamirim, e com isso, o giro de capital não é observado nas cidades menores, muito menos a renda média reflete o real potencial do município.

Estes dados são de extrema importância para os Gestores Públicos, uma vez que considera fatores poucos utilizados nas maiorias das pesquisas, como a estimativa de população e a renda média, trazendo para a discussão a sua importância neste cenário, necessitando-se de um olhar diferenciado sobre os índices aqui representados.

Municípios como São Gonçalo do Amarante e Macaíba, por exemplo, possuem condições de investimento em políticas de desenvolvimentos locais, uma vez que o seu PIB acusa um volume bastante diferenciado em relação a média dos demais municípios. Trata-se de cidades ótimas para trabalhar e pouco interessantes para morar, uma vez que não possuem escolas, hospitais, mobilidade urbana, saneamento básico adequado, entre outros itens que pesam na sua infraestrutura, como nos revela alguns autores supracitados neste contexto, tais como: Bresser-Pereira (2006), Veiga (2005) e Amaral et. al. (2010)

Finalmente, um dado que se torna bastante oportuno discutir neste momento, trata-se da questão do Índice de Desenvolvimento Humano, um dos índices que possui uma aceitação bastante complexa no ambiente acadêmico. De acordo com muitos pesquisadores, seus dados não revelam a atual realidade da região em questão, seja ela um continente, país, estado ou município, porque desconsidera seu possível desvio padrão, generalizando os dados. Observando-se rigorosamente as tabelas 4 e 8 anteriormente apresentadas, verifica-se que entre os municípios mais desenvolvidos e os menos desenvolvidos, o IDH pode ser considerados como médio, algo que foge da realidade deste estudo, quando muitos municípios se encontram praticamente na linha de pobreza, sem condições alguma de competir com outros mais desenvolvidos ou oferecer uma infraestrutura que possibilite um desenvolvimento local em médio prazo. 


\section{ISSN - 2447-178X}

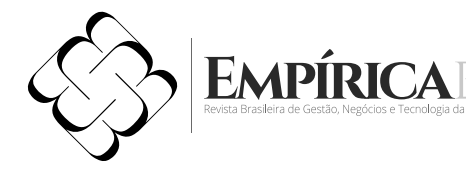

No entanto, estas considerações não podem ser consideradas como uma conclusão finalizada ou uma proposta de solução concreta em que os pesquisadores, gestores, alunos acadêmicos e demais interessados possam utilizar como principal elemento norteador de suas pesquisas. O que se espera com este trabalho é possibilitar uma reflexão sobre a temática estudada a respeito os dados apresentados estatisticamente sobre as condições de cada município do estado do Rio Grande do Norte e perceber que existem vários fatores impossibilitam observar a verdadeira realidade destes municípios e que não podem ser analisados apenas estatisticamente ou por variantes puramente quantitativas. Fontes de renda, condições do solo, atividades sazonais, densidade demográfica, educação, atendimento à saúde são apenas alguns dos fatores que precisam ser observados in loco para depois serem confrontados com os dados estatísticos apresentados para cada município.

\section{REFERÊNCIAS}

1. AMARAL, Reginaldo Gonçalves et. al. Copa do Mundo no Brasil: evento global e desenvolvimento local. Caderno de Ciências Sociais Aplicadas, n. 10, Vitória da Conquista: Edições UESB, ago. 2010 p. 197-214.

2. AZEVEDO, Francisco Fransualdo de. Reestruturação produtiva no Rio Grande do Norte. Mercator, Fortaleza, v.12, n. esp. 2, set. 2013, p. 113-132. Disponível em: <http://www.mercator.ufc.br/index.php/ mercator/article/viewFile/1178/500> Acesso em: 12 abr. 2017.

3. BRESSER-PEREIRA, Luis Carlos. 0 conceito histórico de desenvolvimento econômico.mar. 2006. Disponível em: <http://www.bresserpereira.org.br/papers/2006/06.7ConceitoHistoricoDesenvolvimento.pdf> Acesso em: 15 mai. 2017.

4. BUARQUE, S. Construindo o Desenvolvimento Local sustentável. Metodologia de Planejamento. Rio de Janeiro: Garamond, 2001.

5. DATASUS. Renda Média Domiciliar per capita: Rio Grande do Norte. 2010. Disponível em: <http://tabnet.datasus.gov.br/cgi/tabcgi.exe?ibge/censo/cnv/rendarn.def> Acesso em 20 mai. 2017.

6. FONSECA, Manoel Alcino Ribeiro da. Planejamento e desenvolvimento econômico. São Paulo: Thomson Learning, 2006.

7. GIL, Antônio Carlos. Como elaborar projetos de pesquisa. 5.ed. São Paulo: Atlas, 2010.

8. GOLDEMBERG, José. O repensar da educação no Brasil. Estud. av. vol.7, n.18, São Paulo, mai./ago. 1993. Disponível em: <http://www.scielo.br/scielo.php?script=sci_ arttext\&pid=S0103-40141993000200004> Acesso em: 12 jun. 2017.

9. IBGE. Relatório do $1^{\circ}$ workshop sobre estimativas de população para pequenas áreas. Rio de Janeiro: Fundação Instituto Brasileiro de Geografia e Estatística, Diretoria de Pesquisas, Departamento de População, 1991. 
Rio Grande do Norte. 2016. Disponível em: <http://cidades.ibge.gov.br/xtras/ uf.php?coduf=24> Acesso em: 15 abr. 2017.

11. HOWE, A. Assessing the accuracy of Australia's small area population estimates. Caberra: Australian Population Association - APA, 12th Biennial Conference, 2004.

12. LIMA, Severino Cesário de. Desempenho Fiscal da dívida dos grandes municípios brasileiros. São Paulo, 2011. Tese de Doutorado em Ciências Contábeis. Universidade de São Paulo. Faculdade de Economia, Administração e Contábeis. 193 p.

13. MEDEIROS, Valéria Zuma (org.). Métodos Quantitativos com Excel. São Paulo: Thomson, 2008.

14. NUNES, Paulo. Ciências Econômicas e Empresariais: PIB - Produto Interno Bruto. 09 fev. 2016a. Disponível em: <http://www.knoow.net/cienceconempr/economia/pib.htm> Acesso em: 25 mai. 2017. 15. : IDH (Índice de Desenvolvimento Humano). 09 fev. 2016b. Disponível em: <http:// www.knoow.net/cienceconempr/economia/idh.htm> Acesso em: 25 mai. 2017.

16. PNUD. Programa das Nações Unidas para o Desenvolvimento -. (2012). Desenvolvimento Humano e

17. IDH. Disponível em: <http://www.pnud.org.br/IDH/DH.aspx> Acesso em: 05 mar. 2017.

18. Relatório do Desenvolvimento Humano 2015: o trabalho como motor do desenvolvimento humano. 2015. Disponível em: <http://hdr.undp.org/sites/default/files/hdr15_ overview_pt.pdf> Acesso em: 10 mar. 2017.

19. SANTOMAURO, Beatriz; BIBIANO, Bianca. Governo Federal investe mais em Educação e amplia a escolaridade obrigatória. 2009. Disponível em: <https://novaescola.org.br/conteudo/2963/governofederal-investe-mais-em-educacao-e-amplia-a-escolaridade-obrigatoria > Acesso em: 5 mai. 2017.

20. SISTEMA FIERN. Diagnóstico e cenários de desenvolvimento econômico para o Rio Grande do Norte: 2015-2035. fev. 2014. Disponível em: < Acesso em: 15 ago. 2017.

21. VEIGA, José Eli da. Desenvolvimento Sustentável: o desafio do século XXI. Rio de Janeiro: Garamond, 2010. 